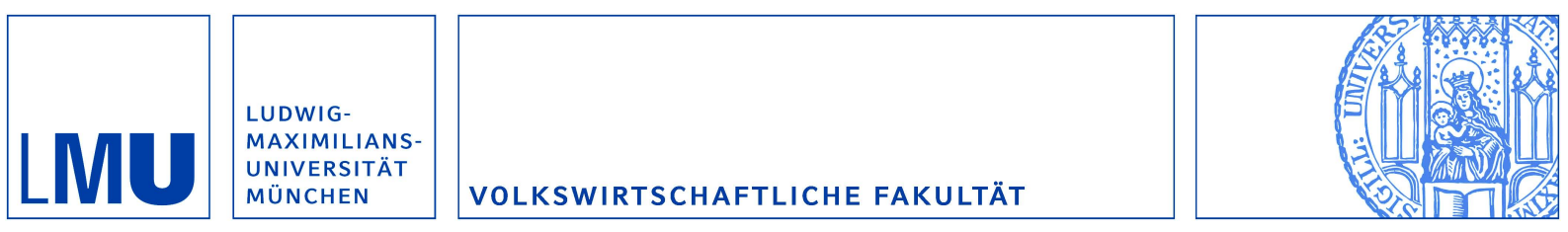

Reisinger, Markus und Schnitzer, Monika:

A Model of Vertical Oligopolistic Competition

Munich Discussion Paper No. 2008-8

Department of Economics

University of Munich

Volkswirtschaftliche Fakultät

Ludwig-Maximilians-Universität München

Online at https://doi.org/10.5282/ubm/epub.3189 


\title{
A Model of Vertical Oligopolistic Competition*
}

\author{
Markus Reisinger ${ }^{\dagger}$ and Monika Schnitzer ${ }^{\ddagger}$
}

February 2008

\begin{abstract}
This paper develops a model of successive oligopolies with endogenous market entry, allowing for varying degrees of product differentiation and entry costs in both markets. Our analysis shows that the downstream conditions dominate the overall profitability of the two-tier structure while the upstream conditions mainly affect the distribution of profits. We compare the welfare effects of upstream versus downstream deregulation policies and show that the impact of deregulation may be overvalued when ignoring feedback effects from the other market. Furthermore, we analyze how different forms of vertical restraints influence the endogenous market structure and show when they are welfare enhancing.
\end{abstract}

JEL classification: L13, D43, L40, L50

Keywords: Deregulation, Free Entry, Price Competition, Product Differentiation, Successive Oligopolies, Two-Part Tariffs, Vertical Restraints

${ }^{*}$ We would like to thank Gergely Csorba, Guido Friebel, Felix Höffler, Simon Lörtscher, Salvatore Piccolo, Michael Raith, Ray Rees, Patrick Rey, Ingo Vogelsang and the participants at the Universities of Mannheim, Melbourne, Munich and Toulouse, the Social Science Center in Berlin, at the Swiss IO Day 2007 (Bern), ESEM 2007 (Budapest), and E.A.R.I.E. 2007 (Valencia) for very helpful comments and suggestions. Both authors gratefully acknowledge financial support from the German Science Foundation through SFB/TR 15. Part of this paper has been written while the first author visited the IDEI in Toulouse which he thanks for the hospitality and stimulating discussions.

${ }^{\dagger}$ Department of Economics, University of Munich, Kaulbachstr. 45, 80539 Munich, Germany, e-mail: markus.reisinger@lrz.uni-muenchen.de.

${ }^{\ddagger}$ Department of Economics, University of Munich, Akademiestr. 1/III, 80799 Munich, Germany, e-mail: schnitzer@lrz.uni-muenchen.de 


\section{Introduction}

The structure of input and output markets varies a lot between different industries. In some industries, output producers operate in a very competitive environment while input suppliers do not, in others it is the other way round. ${ }^{1}$ Still others have oligopolistic structures with a small number of firms in both the input and output markets. ${ }^{2}$ Yet there is little knowledge about how these competitive structures evolve and, in particular, how the competitive environment in output markets affects competition in the input market and vice versa.

Understanding the interaction between upstream and downstream markets is also important for policy issues, like deregulation. During the last decade, governments in all OECD countries have pursued a policy of deregulation. ${ }^{3}$ But experiences have been mixed. In the natural gas market in the U.S., for example, prior to deregulation, consumer prices had increased a lot. Deregulation of the downstream retail market led to market entry in the downstream as well as in the upstream market, and a stabilization of consumer prices. In the electricity market in Germany, deregulation of the downstream retail market led to entry in the downstream market as well and to a fall in consumer prices. But in contrast to the U.S. example, this downstream entry was followed by a merger wave in the upstream market and a subsequent increase in consumer prices. These examples suggest that policymakers have to be aware of the potential feedback effects that deregulation of one market may have on the other market.

Similarly, the welfare effects of different forms of vertical restraints can only be judged correctly if endogenous changes in the market structure stemming from these restraints are taken into account. Some forms, like two-part tariffs, are generally perceived as welfare enhancing, because they avoid double marginalization. Others, like resale price maintenance (RPM), are illegal in most countries because they are commonly expected to reduce competition and result in higher prices. ${ }^{4}$ However, the existing literature focusses on given market structures and ignores the potential effects these

\footnotetext{
${ }^{1}$ E.g., in the electricity market, after deregulation, consumers in many U.S. and European regions can choose between many electricity marketers. These marketers in turn buy from only a few big electricity producing companies. In contrast, the automobile and aviation industry are examples of industries where, for many components, a large number of suppliers are confronted with only a small number of final goods producers.

${ }^{2}$ An example is the market for the micro processors of personal computers. There are only few firms producing micro processors, mainly Intel Corporation and Advanced Micro Devices, Inc. (AMD), while the number of personal computer manufacturers is a bit larger but also small.

${ }^{3}$ See e.g. Nicoletti and Scarpetta (2003). The World Bank report "Doing Business 2007" documents that, from 2003 to 2007, 238 market reforms were introduced in 175 countries. 213 of these reforms facilitate business activities.

${ }^{4}$ In Europe, RPM is illegal per se. In the U.S., it was illegal until recently when the Supreme Court struck down a law that would completely prohibit manufacturers to engage in this practice.
} 
practices may have on market entry. Supporters of RPM for example object that it can help promote competition via entry of new firms. Thus, a model is required that allows us to study how different competitive environments, pricing strategies and policy choices affect the overall market outcome when market structures upstream and downstream evolve endogenously.

In this paper, to address these kinds of questions, we provide a model of successive oligopolies with endogenous market entry. We allow for varying degrees of product differentiation and different entry costs in both markets, reflecting different competitive environments in the two markets. Thus, we can use the model to explore the endogenous two-tier market structure as a function of both product differentiation and entry cost in the two markets for different forms of vertical contracts. Despite being more general in this respect than existing models, our model can still be solved analytically rather than having to resort to numerical solutions.

The idea of our theoretical approach is to model each market like a Salop circle with free entry. Such a model is straightforward to analyze if market demand can be assumed to be continuous. For downstream firms selling to a large number of consumers, this assumption is innocuous. However, the analysis is less straightforward for the upstream market where demand is generated by only a finite number of input buyers, as this may give rise to potential discontinuities in the demand function. The theoretical innovation of our model is to find a specification that makes demand in the upstream market continuous. We achieve this goal by introducing uncertainty about the location of buyers. An upstream firm sells to every downstream firm with positive probability, and this probability is continuously decreasing in its price. Although solving the model is analytically involved, the solutions are remarkably simple and intuitive. We also show that there exists a unique equilibrium under any form of vertical contracting. This allows us to give clear comparative static predictions, and, most importantly, it enables us to study the welfare implications of different contracts.

We derive several results on how the competitive conditions in one market affect the conditions in the other market and the overall market structure. For instance, as one would intuitively expect, a more competitive upstream market induces lower upstream prices and thereby leads to more market entry and lower prices downstream. On the other hand, matters are not so clear when the consequences of increased downstream competition on the upstream market are considered. Here we find that a larger number of downstream firms has both positive and negative effects on upstream profits. First, more potential buyers are present, which has a positive effect on upstream firms, but second, competition becomes fiercer and this puts downward pressure on the upstream prices. We show that 
the first effect dominates if few downstream firms are present, and the second one dominates if the number of downstream firms is large. We also provide examples of different industries in different countries where these effects can be observed. Overall, we find that the competitive conditions in the downstream market dominate the profitability of the two-tier structure while the competitive conditions in the upstream market mainly affect the distribution of profits.

We can then use the model to evaluate deregulation policies, explicitly taking into account the feedback effects between the two markets. This allows us first to explain the conflicting observations from recent deregulation cases pointed out above. Second, we can also address the question of whether it is best to encourage competition downstream, despite its potentially negative effect on market entry in the upstream market, or to encourage it upstream, counting on its positive impact on downstream competition. The answer is straightforward if the competitive structures upstream and downstream differ a lot, but it is less obvious if the structures of the input and output markets are similar. Our analysis reveals that, if the overall number of firms, upstream and downstream, is small, deregulation downstream is more effective. The reason is that, in this case, the feedback effects via the upstream market are positive while upstream deregulation has little effect on downstream prices if downstream competition is low. In contrast, upstream deregulation is preferable if the overall number of firms is large.

Finally, we study the welfare implications of different forms of vertical restraints, namely two-part tariffs and resale price maintenance. Our analysis shows that the welfare effects under exogenously given market structures can differ substantially from those under endogenously evolving ones. In particular, we find that welfare under linear pricing can be higher than under two-part tariffs, even though, as is commonly known (see e.g. Villas-Boas (2007)), the latter avoids double marginalization. This is due to the fact that entry in the downstream market is larger under linear pricing and so downstream competition is fiercer. Moreover, we show that the welfare under two-part tariffs is larger than under resale price maintenance although the latter induces more market entry. Here the effect of double marginalization dominates.

The existing literature that deals with vertical market structures is mostly interested in the question of under which conditions different forms of vertical relations, like integration or vertical contracts, arise. In this literature the basic markets are modelled in a simplified way, with an exogenous number of firms in each market, often only two firms upstream and downstream, and homogeneous products in at least one market. For example, dealing with vertical integration Greenhut 
and Ohta (1979), Salinger (1988) and Gaudet and van Long (1996)analyze markets with homogeneous goods and competition à la Cournot to assess the implications of vertical mergers. Ordover, Saloner and Salop (1990) and Chen (2001) allow for price competition in a framework with vertical integration. Assuming homogeneous products in the upstream market and restricting the number of downstream firms to two, they show that, in this framework, it is possible to generate asymmetric equilibria in which one firm is integrated and the other one is not.

There are several papers that deal with vertical contracting issues and their welfare implications, e.g. Hart and Tirole (1990), McAfee and Schwartz (1992) or White (2007). These studies mainly assume a monopolistic upstream supplier and analyze whether it is able to extract monopoly rents on the downstream market where a given number of firms compete. In contrast to these papers, our focus is on determining the market structure endogenously in order to show how the possibility of having different forms of contracts affects the overall structure and to provide policy implications whether these contracts are welfare enhancing.

A recent paper that analyzes a market structure similar to ours, with oligopolistic competition upstream and downstream, is Hendricks and McAfee (2007). They assume Cournot competition with homogeneous goods and allow for a general number of firms. Additionally, firms in the downstream market exert market power both upstream and downstream. Downstream firms are uncertain about the cost function of an upstream firm while upstream firms are uncertain about the valuation of a downstream firm. Thus, upstream firms can overstate their costs and downstream firms can understate their valuations. In order to get explicit results, Hendricks and McAfee (2007) employ a supply function approach. In contrast to our paper, they allow for oligopsonistic power of the downstream firms in the input market but, due to their assumption of homogeneous products and Cournot competition, they cannot determine how the market structure evolves endogenously under varying degrees of substitutability. Moreover, it is not possible in their framework to compare the welfare implications of different forms of vertical contracts. ${ }^{5}$

To sum up, the existing literature does not provide a general framework for dealing with the question of how vertically interrelated oligopolies work and for assessing the welfare consequences of vertical restraints that can change the market structure. One of the reasons for this lack of more

\footnotetext{
${ }^{5}$ Eső, Nocke and White (2007) consider a different but related question. They analyze a downstream industry in which firms compete for a scarce input good. They show that, if the supply of this input good is large enough, the resulting industry structure is asymmetric with one firm being larger than the others. In contrast to our paper, they do not model the upstream market explicitly but rather assume that the input is allocated efficiently from the perspective of the downstream firms. As a consequence, in their model the interrelation between the two markets is not present.
} 
generality is that such models quickly become very complicated. A contribution of this paper is to provide such a general model that can serve as a framework for addressing a variety of questions. In this paper we use the model to compare deregulation effects and the welfare implications of different pricing regimes. Other applications could be globalized markets and their impact on the evolution of industry structures or the analysis of supply chains or vertical integration. ${ }^{6}$

The remainder of the paper is organized as follows. The next Section sets out the model. In Section 3 we solve for the subgame perfect equilibrium of the model with linear pricing. Section 4 studies the interplay of the upstream and the downstream markets, providing comparative statics for the two-tier market structure and exploring the relative welfare effects of upstream and downstream deregulation. Three examples from different industries and countries are given. In Section 5 we study the model under two forms of vertical restraints, two-part tariffs and resale price maintenance, with a particular focus on their welfare implications. Section 6 concludes.

\section{The Model}

Consider an industry with two successive oligopolies, an upstream and a downstream market. In the upstream market each firm produces an intermediate good at marginal cost that is normalized to zero. The upstream firms sell the intermediate goods to the downstream firms, the producers of the final good. Downstream firms transform the intermediate goods into output at zero costs on a one-to-one basis. ${ }^{7}$

There is free entry in both markets, but all firms that enter in the upstream market must incur a fixed set-up cost of $F_{u}>0$ while firms entering in the downstream market must incur a fixed set-up $\operatorname{cost} F_{d}>0$. The number of firms that enter in each market is endogenous and we denote the number of upstream firms by $m$ and the number of downstream firms by $n$. For simplicity, we treat $n$ and $m$ as continuous variables. This implies that, in equilibrium, the profit of each firm net of set-up cost is zero.

An upstream firm $i$ sells its intermediate good to the downstream firms at a price per unit that is denoted by $r_{i}, i \in(1, \ldots, m){ }^{8}$ Similarly, we denote a downstream firm $j$ 's final good price by

\footnotetext{
${ }^{6}$ See the conclusion for a discussion of these issues.

${ }^{7}$ The normalization of zero marginal cost in the upstream and the downstream markets is without loss of generality. All qualitative results remain unchanged, if we assume constant marginal costs of $c_{u}>0$ and/or $c_{d}>0 \mathrm{instead}$,

${ }^{8}$ There are two reasons to analyze the case of linear pricing in more detail. First, in many vertical structures, linear pricing is the prevalent practice, like in the three industries we describe in more detail in Section 4.5. Second, linear pricing is a useful benchmark against which to compare the results of more elaborate pricing schemes that we analyze
} 
$p_{j}, j \in(1, \ldots, n)$.

First we describe the downstream market. We model the downstream market in a way similar to Salop (1979). There exists a continuum of consumers of mass 1 that is uniformly distributed on a circle with unit circumference. A consumer who is located at $z$ and purchases the good from firm $j$ located at $z_{j}$ incurs total cost of $p_{j}+t_{d}\left(z-z_{j}\right)^{2}$. We assume that the gross utility of consuming the good is sufficiently high so that all consumers buy for the range of prices considered. $t_{d}\left(z-z_{j}\right)^{2}$ is the disutility that a consumer incurs if she does not buy her most preferred variety. This disutility is assumed to be quadratic in the distance between the consumer and the firm. ${ }^{9}$ The $n$ downstream firms are equidistantly distributed. So the marginal consumer between firms $j$ and $j+1$ lies at distance $z_{m}$ from firm $j$, with

$$
z_{m}=\frac{1}{2 n}+\frac{n\left(p_{j+1}-p_{j}\right)}{2 t_{d}} .
$$

We now turn to the upstream market. Here again, we consider a Salop circle on which the sellers, the upstream firms, are located with equal distance from each other. The buyers in the upstream market are the downstream firms. We first specify the costs a downstream firm incurs when buying its intermediate goods. Then we describe the location of downstream firms as customers in the upstream market.

When buying from upstream firm $i$, a downstream firm $j$ faces per unit cost of $r_{i}$ for the intermediate good and, additionally, a fixed cost that is given by $t_{u}\left(x_{j}-x_{i}\right)^{2}$, where $t_{u}$ is transportation cost in the upstream market and $\left(x_{j}-x_{i}\right)^{2}$ is the shortest arc length between the location of firm $j$ and the location of firm $i$ in the upstream market. These fixed costs reflect how well the intermediate good of firm $i$ fit the particular needs of the final good producer $j$. For instance, the characteristics of the good provided by firm $i$ may not exactly fit the technology of firm $j$ and so firm $j$ must incur costs to reposition its machine. ${ }^{10}$

In contrast to the downstream market, there are only a finite number of buyers in the upstream market instead of a continuum. This could potentially lead to discontinuities in the demand curve in Section 5.

${ }^{9}$ With this assumption, we avoid the well-known problem that the profit function of firm $j$ becomes discontinuous if its price is low enough so that the consumer located exactly at the position of its neighboring firm $j-1$ or $j+1$ prefers to buy from firm $j$ rather than from firm $j-1$ or $j+1$. All our results also hold for the case of linear transport costs under the additional assumption that $t_{d}$ is sufficiently high.

${ }^{10}$ We could also incorporate the location distance between firm $i$ and $j$ as a variable cost. But this makes the model technically more complicated without gaining new insights. The reason is that, with such a formulation, the travel distances enter the maximization problem of a downstream firm in a non-linear way. Instead, in our simpler specification, the travel distance only determines the choice of the input supplier and has no direct influence on the maximization problem in the downstream market. 
of an upstream firm. ${ }^{11}$ In order to deal with this problem, we suppose that, at the time when upstream firm $i$ decides about its price for the intermediate good, it does not know the locations of the downstream firms in the upstream market. Instead, it expects each point in the upstream circle to be equally likely as a location for a downstream firm, i.e. the expected location is uniformly distributed over the upstream circle. With this specification, demand functions are continuous. It conveys the idea that the intermediate good of an upstream firm is suitable for producing many different output goods and so firm $i$ is ex ante uncertain if a downstream firm will buy from it or from its rivals. ${ }^{12}$

We also assume that, when choosing its input supplier, each downstream firm knows its own location in the upstream market but does not observe the location of other downstream firms. Instead, like an upstream firm, it expects the location of every other downstream firm to be uniformly distributed on the upstream circle. An obvious reason for this is that a firm usually does not know the exact production technology of its rivals and so does not know which input best fits their needs. An implication of this assumption is that the location of a downstream firm in the upstream market is independent of its location in the downstream market. This reflects the idea that different locations of downstream firms in the upstream market stem from different technologies while a difference in the locations in the downstream market emerges due to production of different varieties or represents a geographic distance. ${ }^{13}$ As a consequence of this assumption, a downstream firm cannot observe the input suppliers from which its rival downstream firms are buying and so it does not observe their input prices.

Thus, after observing the upstream price vector $\mathbf{r}$, downstream firm $j$ forms expectations about the profit it earns in the product market when buying from supplier $i, E\left[\Pi_{j}(\mathbf{r})\right]$. As a consequence, firm $j$ buys from supplier $i$ if ${ }^{14}$

$$
\begin{gathered}
E\left[\Pi_{j}^{i}\left(r_{i}, r_{-i}\right)\right]-t_{u}\left(x_{j}-x_{i}\right)^{2} \geq \\
E\left[\Pi_{j}^{k}\left(r_{k}, r_{-k}\right)\right]-t_{u}\left(x_{j}-x_{k}\right)^{2}, \quad \forall k \neq i .{ }^{15}
\end{gathered}
$$

\footnotetext{
${ }^{11}$ For an in-depth discussion of that problem, see e.g. Gabszewicz and Thisse (1986).

${ }^{12}$ For example, a microprocessor of Intel or AMD is suitable for almost all models of personal computers and notebooks that are produced by computer manufacturers like Dell, Hewlett \& Packard or Acer. But, ex ante, it is not clear which processor the computer manufacturer will use for the specific model.

${ }^{13}$ For example, in the market for batteries, Duracell and Valance Technologies are close competitors. Yet, Valance Technologies uses a completely different technology than Duracell because, in contrast to Duracell, it engages in $\mathrm{R} \&$ $\mathrm{D}$ on batteries. Therefore, the two firms need a different set of inputs and are not closely located to each other in the input market.

${ }^{14}$ Here, and in the following, $r_{-i}$ denotes the prices of all upstream firms except firm $i,\left\{r_{1}, \ldots, r_{i-1}, r_{i+1}, \ldots, r_{m}\right\}$.

${ }^{15} \mathrm{We}$ restrict attention to those cases where the upstream market is fully covered, i.e. each downstream firm buys
} 
It follows that the probability that firm $j$ buys its intermediate good from firm $i$ is given by ${ }^{16}$

$$
q_{i}=\left(\frac{1}{m}+\frac{m\left(2 E\left[\Pi_{j}^{i}\right]-E\left[\Pi_{j}^{i-1}\right]-E\left[\Pi_{j}^{i+1}\right]\right)}{2 t_{u}}\right) .
$$

To make the problem interesting, we finally assume that the fixed set-up costs are low enough such that in both markets at least two firms enter. It turns out that this is fulfilled if ${ }^{17}$

$$
F_{d}<\frac{1}{8}\left(t_{d}-\frac{t_{u}}{6}\right) \quad \text { and } \quad F_{u}<\frac{t_{u}}{3\left(t_{u}+12 F_{d}\right)} \sqrt[3]{48\left(48 F_{d}+t_{u}\right)^{2}}
$$

We consider the following three stage game. In the first stage a large number of firms can enter either in the upstream or in the downstream market at the respective set-up costs $F_{u}$ and $F_{d}$. After entry, both upstream and downstream firms are symmetrically distributed in their respective markets. The location of the downstream firms as customers in the upstream market is uncertain and each downstream firm can be distributed over the whole circle with equal probability. In the second stage, upstream firms set their prices $r_{i}$. Afterwards, downstream firms learn their position in the upstream market and choose their preferred supplier of the intermediate good but they do not learn the positions of all rival downstream firms. In stage three, downstream firms set prices in the downstream market.

\section{Equilibrium of the Model}

In this section we describe the solution of the three stage game. We solve the game by backward induction. A rigorous proof of the results can be found in Appendix A.

\section{Downstream Market}

In stage three, each downstream firm decides on its final good price, knowing $n$ and $m$ and the upstream price vector $\mathbf{r}$. When setting its price $p_{j}$, downstream firm $j$ does not observe from which upstream firms its two neighboring firms buy the intermediate good, and so it does not observe their input prices. Since input prices influence final good prices, downstream firms that buy from different upstream firms might set different final good prices. However, in equilibrium, firm $j$ knows the expected input price of its rivals. Anticipating that, in equilibrium, all competitors with the same input price will charge the same output price, it also knows the expected output price. ${ }^{18}$ As a

from one of the upstream firms, even if it is located at maximum distance to the supplies, namely exactly between two of them. It turns out that a sufficient condition for this to hold is $t_{u}<\left(48 F_{d}\right) / 5$ (see footnote 21 ).

${ }^{16}$ For the sake of notation we abbreviate $E\left[\Pi_{j}^{i}\left(p_{j}, p_{-j}, r_{i}, r_{-i}\right)\right]$ by $E\left[\Pi_{j}^{i}\right]$.

${ }^{17}$ Footnote 22 explains how these conditions are derived.

${ }^{18}$ For models with a similar structure, see Raith (2003), Aghion and Schankerman (2004), or Syverson (2004). 
consequence, the expected profit of firm $j$ (gross of fixed costs) when buying its input from upstream firm $i$ can be written as

$$
E\left[\Pi_{j}^{i}\left(p_{j}, r_{i}, p_{j-1}, p_{j+1}\right)\right]=\left(p_{j}-r_{i}\right)\left(\frac{1}{n}+\frac{n\left(E\left[p_{j-1}\right]+E\left[p_{j+1}\right]-2 p_{j}\right)}{2 t_{d}}\right) .
$$

This maximization problem is identical for all downstream firms, with the exception that they potentially face different input prices. Thus, in a symmetric equilibrium there can be at most $m$ different downstream prices. Since the expectation about the upstream location of its two neighbors is the same, firm $j$ 's expectation about $E\left[p_{j-1}\right]$ and $E\left[p_{j+1}\right]$ is the same and is given by $\sum_{k=1}^{m} q_{k} p_{k}$, where $p_{k}$ is the price that a downstream firm charges when buying the input from upstream firm $k .{ }^{19}$ Since this holds for all downstream firms, the expected profit of a downstream firm that buys the input from upstream firm $i$ can then be written as

$$
E\left[\Pi^{i}\left(p_{i}, r_{i}, p_{-i}\right)\right]=\left(p_{i}-r_{i}\right)\left(\frac{1}{n}+\frac{n\left(\sum_{k=1}^{m} q_{k} p_{k}-p_{i}\right)}{t_{d}}\right), \quad i \in\{1, \ldots, m\} .
$$

Maximizing the last equations with respect to $p_{i}$ gives a system of $m$ equations. Solving this system for $p_{i}$ gives

$$
p_{i}=\frac{1}{2}\left(r_{i}+\sum_{k=1}^{m} q_{k} r_{k}+\frac{2 t_{d}}{n^{2}}\right), \quad i \in\{1, \ldots m\} .
$$

Plugging these prices back into the respective profit functions gives the expected profit of all downstream firms dependent on $r_{i}$ and $q_{i}, i \in\{1, \ldots, m\}$. Since the probabilities are functions of the downstream profits, we can solve for these probabilities by plugging the profits into (1). The general formula for $q_{i}$ is not very enlightening, and is therefore only given in Appendix A by equation (14) for the case that $m \geq 3$ and by (15) for the case of $m=2$. Inserting this formula back into the profit function, we can derive the output price that downstream firm $j$ charges when it buys from upstream firm $i, p_{i}\left(r_{i}, r_{-i}\right)$, and the quantity that it buys, denoted by $y_{i}\left(r_{i}, r_{-i}\right)$. These expressions are given by equations (16) and (18) in Appendix A for the case $m \geq 3$ and by (17) and (19) for the case that $m=2$. Having solved the third stage of the game, we now proceed to the second stage, the upstream market.

\section{Upstream market}

Since production costs are equal to zero, the profit of an upstream firm $i$ can be written as the probability that it sells to exactly one downstream firm multiplied by the revenue, $r_{i} y_{i}\left(r_{i}, r_{-i}\right)$, plus

\footnotetext{
${ }^{19}$ Recall that $q_{k}$ is the probability that a downstream firm buys from upstream firm $k$.
} 
the probability that it sells to exactly two downstream firms multiplied by twice the revenue and so forth. This can be written $\operatorname{as}^{20}$

$$
\begin{aligned}
& E\left[P_{i}\left(r_{i}, r_{-i}\right)\right]=r_{i} y_{i}\left(\left(\begin{array}{c}
n \\
1
\end{array}\right) q_{i}\left(1-q_{i}\right)^{n-1}+2\left(\begin{array}{c}
n \\
2
\end{array}\right) q_{i}^{2}\left(1-q_{i}\right)^{n-2}+\right. \\
& \left.+\cdots+(n-1)\left(\begin{array}{c}
n \\
n-1
\end{array}\right) q_{i}^{n-1}\left(1-q_{i}\right)+n q_{i}^{n}\right), \quad i \in\{1, \ldots m\} .
\end{aligned}
$$

Using a modification of the Binomial Theorem, the profit function simplifies to

$$
E\left[P_{i}\left(r_{i}, r_{-i}\right)\right]=r_{i} y_{i} n q_{i}, \quad i \in\{1, \ldots m\}
$$

We can now substitute the respective expressions for $y_{i}$ and $q_{i}$ that we determined in the third stage and maximize (3) with respect to $r_{i}$. Since the profit function is the same for all upstream firms, the equilibrium is symmetric. Solving for the equilibrium upstream price gives a remarkably simple formula:

$$
r^{\star}=\frac{2 t_{u} t_{d} m n}{t_{u} n^{3}(m-1)+2 m^{3} t_{d}} .
$$

The equilibrium upstream price can then be inserted into the formula for the downstream price to get

$$
p^{\star}=\frac{t_{d}\left(2 m^{3} t_{d}+t_{u} n^{3}(3 m-1)\right)}{n^{2}\left(2 m^{3} t_{d}+t_{u} n^{3}(m-1)\right)} .
$$

\section{Entry Decision}

The equilibrium number of upstream and downstream firms, $n^{\star}$ and $m^{\star}$, is determined by the zeroprofit conditions in the upstream and the downstream market. Inserting the equilibrium prices into the profit functions yields that $n^{\star}$ and $m^{\star}$ are implicitly given by ${ }^{21}$

$$
\frac{t_{d}}{\left(n^{\star}\right)^{3}}-\frac{t_{u}}{12\left(m^{\star}\right)^{2}}-F_{d}=0
$$

and

$$
\frac{2 t_{u} t_{d} n^{\star}}{t_{u}\left(n^{\star}\right)^{3}\left(m^{\star}-1\right)+2\left(m^{\star}\right)^{3} t_{d}}-F_{u}=0
$$

\footnotetext{
${ }^{20}$ For notational simplicity we suppress the dependence of $y_{i}$ and $q_{i}$ on $r_{i}$ and $r_{-i}$.

${ }^{21}$ The inequality in footnote 15 is derived from (6). The largest possible distance of a downstream firm to its input supplier arises when $m^{\star}=2$. The distance is then $1 / 4$. In this case the downstream firm's profit after entering is still positive if $t_{d} /\left(n^{\star}\right)^{3}-t u / 16>0$. Solving (6) for $n^{\star}$ under the case $m^{\star}=2$, plugging it into the last inequality and simplifying yields $t_{u}<\left(48 F_{d}\right) / 5$. Naturally, if $m^{\star}>2$ the constraint on $t_{u}$ is less tight.
} 
Our assumptions on $F_{d}$ and $F_{u}$ above guarantee that at least two firms enter in each market. ${ }^{22}$ We now examine whether or not the equilibrium is unique. For this purpose, we use the iso-profit-lines of downstream and upstream firms. For a downstream firm, the slope of its iso-profit line is given by

$$
\frac{\partial n}{\partial m}=\frac{t_{u}(n)^{4}}{18 t_{d}(m)^{3}}>0
$$

Thus, the equilibrium number of downstream firms increases with the number of upstream firms. The intuition for this is simple. If the number of upstream firms increases, downstream firms benefit from lower input prices and expect to face a lower travel distance to their nearest upstream firm. As a consequence, more firms enter the downstream market. This is depicted by the iso-profit-line $I_{D}$ in Figure 1. Note that the zero profit condition in the downstream market could be achieved by e.g. many upstream and downstream firms, but also by few upstream and downstream firms.

For an upstream firm, the slope of the iso-profit-line is given by

$$
\frac{\partial m}{\partial n}=\frac{2\left((m)^{3} t_{d}-t_{u}(n)^{3}(m-1)\right)}{n\left(t_{u}(n)^{3}+6 t_{d}(m)^{2}\right)} .
$$

Here the sign is ambiguous. Inspection of (9) reveals that it is negative if $n \geq \sqrt[3]{\left(t_{d} m\right) /\left(t_{u}(m-1)\right)} m$, while it is positive if the reverse holds true. The reason for this ambiguity is that a change in the number of downstream firms has two effects on the profit of an upstream firm.

Since downstream firms compete against each other, a larger number of downstream firms implies a larger number of marginal consumers in the output market. If an upstream firm lowers its price, the downstream firms that buys from this firm sell a higher quantity, and this quantity increase is the larger, the more marginal consumers exist in the downstream market. Thus, each upstream firm has a bigger incentive to lower its price and this increased competition effect lowers upstream profits. ${ }^{23}$

On the other hand, with a larger number of downstream firms each upstream firm faces more potential buyers. An upstream firm potentially cannibalizes its own demand with a price reduction when selling to more than one firm. This is due to the fact that, with some probability, its buyers are neighbors in the product market and so a price cut does not increase demand on the margin

\footnotetext{
${ }^{22}$ The restrictions on $F_{d}$ and $F_{u}$ in (2) are derived from (6) and (7). Since $n^{\star}$ is increasing in $m^{\star}$ (see below), the condition on $F_{d}$ assures that at least two downstream firms enter given that there are only two upstream firms. The condition on $F_{u}$ is derived by solving (6) for $n^{\star}$, plugging this into (7), and setting $m^{\star}=2$.

${ }^{23}$ The effect that upstream profits decrease in the number of downstream firms also arises in Rey and Tirole (2007). They consider a monopolistic upstream supplier that is able to use non-linear tariffs. The monopolist wants to restrict the output to the monopoly quantity but faces a commitment problem not to sell more. This problem gets more severe the more downstream firms are present. Instead, our result does not rely on a commitment effect but on increased competition that carries over to the upstream market. So the results can be seen as complementary to each other.
} 


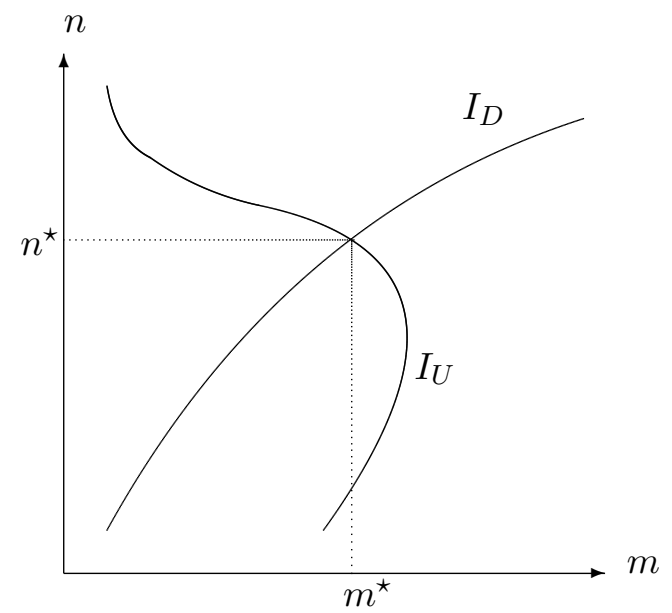

Figure 1: Equilibrium number of firms, $n^{\star}$ and $m^{\star}$

between two buyers. If the number of downstream firms increases, this effect dampens the pressure on upstream prices. Overall, this second effect dominates if the number of downstream firms is small. This is the case because the increased competition effect is more detrimental to profits the larger the number of downstream firms. Therefore, $m$ increases in $n$ if $n$ is small, and it decreases in $n$ if $n$ is large. This is shown by the $I_{U}$-curve in Figure 1 . Thus, for the upstream market we find that the same number of upstream firms can be part of an equilibrium with both a low and a high number of downstream firms.

This non-monotonicity of the $I_{U}$-curve raises the issue of potential multiplicity of equilibria. Multiple equilibria could exist if the two functions cross more than once. However, it is easy to show that this can never be the case. Thus, the equilibrium is unique.

The following proposition summarizes the equilibrium.

\section{Proposition 1}

There exists a unique symmetric subgame perfect equilibrium of the three stage game. In this equilibrium, the number of entering upstream and downstream firms, $n^{\star}$ and $m^{\star}$, is implicitly defined by

$$
\frac{t_{d}}{\left(n^{\star}\right)^{3}}-\frac{t_{u}}{12\left(m^{\star}\right)^{2}}=F_{d} \text { and } \frac{2 t_{u} t_{d} n^{\star}}{t_{u}\left(n^{\star}\right)^{3}\left(m^{\star}-1\right)+2\left(m^{\star}\right)^{3} t_{d}}=F_{u} .
$$

Upstream firms charge a price of

$$
r^{\star}=\frac{2 t_{u} t_{d} m^{\star} n^{\star}}{t_{u}\left(n^{\star}\right)^{3}\left(m^{\star}-1\right)+2\left(m^{\star}\right)^{3} t_{d}}
$$


while downstream firms charge a price of

$$
p^{\star}=\frac{t_{d}\left(2\left(m^{\star}\right)^{3} t_{d}+t_{u}\left(n^{\star}\right)^{3}\left(3 m^{\star}-1\right)\right)}{\left(n^{\star}\right)^{2}\left(2\left(m^{\star}\right)^{3} t_{d}+t_{u}\left(n^{\star}\right)^{3}\left(m^{\star}-1\right)\right)} .
$$

Proof: See Appendix A.

\section{Interplay between Upstream and Downstream Market}

In this section we analyze first how a change in the set-up costs and the degree of competition in each market affect the overall structure. Then we ask to what extent the welfare implications of fostering competition in the downstream market are over- or underestimated when ignoring the interplay with the upstream market. We go on to study at which market level stimulating competition via deregulation is more effective, and, finally, give deregulation examples from different industries and countries that illustrate the described effects.

\subsection{Feedback Effects between Upstream and Downstream Competition}

Consider first a change in the degree of competition and the set-up costs of the upstream market.

\section{Proposition 2}

(i) The equilibrium number of upstream firms is increasing in $t_{u}$ and decreasing in $F_{u}$.

(ii) The equilibrium number of downstream firms is decreasing in $t_{u}$ and in $F_{u}$.

Proof: See Appendix B.

The effects of $t_{u}$ and $F_{u}$ on the equilibrium number of upstream firms are straightforward. A lower degree of competition raises profits in the upstream market and so $m^{\star}$ increases. Higher market entry cost instead lower profits and hence $m^{\star}$ decreases. ${ }^{24}$

For the downstream market, an increase in $t_{u}$ means higher transportation cost and hence lower profits. Although this effect is partly offset by the increase in upstream firms, the direct effect dominates and so $n^{\star}$ decreases. Graphically, an increase in $t_{u}$ shifts the $I_{U}$-curve to the right and the $I_{D}$-curve downwards. This is depicted by the left hand side of Figure 2. Similarly, an increase in $F_{u}$ resulting in fewer upstream firms translates into higher expected travel cost for the downstream firms and so their number goes down as well (see the right hand side of Figure 2). Put differently,

\footnotetext{
${ }^{24} \mathrm{~A}$ decrease in the number of firms can be interpreted as either some firms shutting down and exiting the market or, as is more prevalent, firms merging and the industry getting more concentrated.
} 

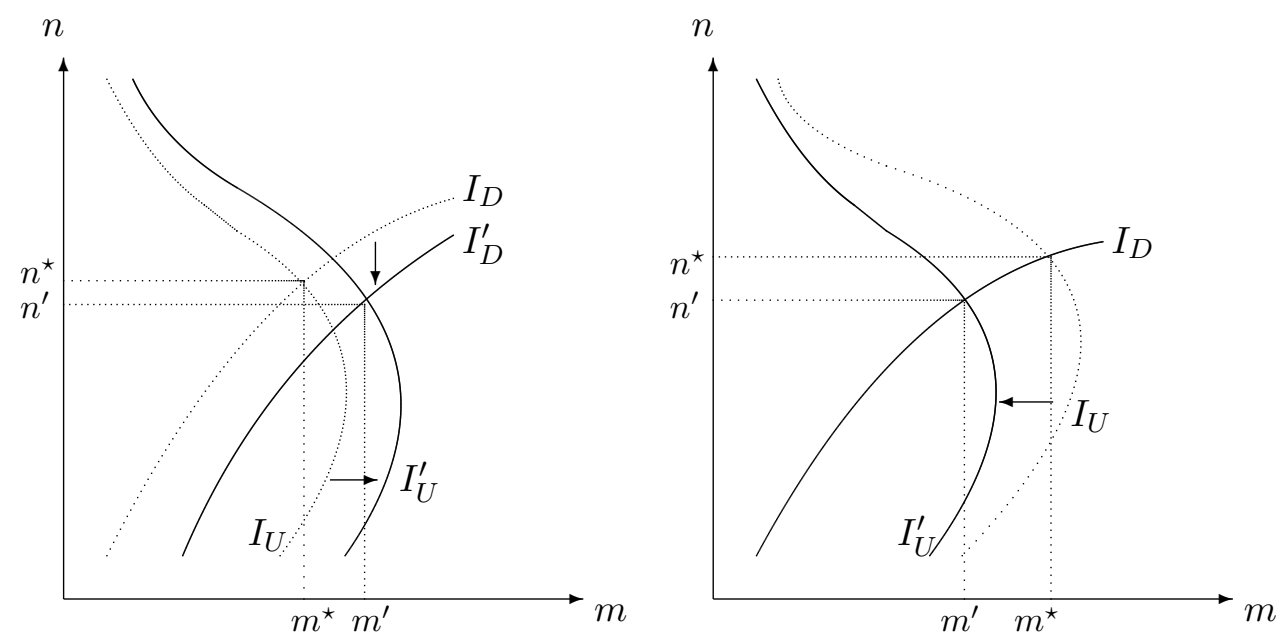

Figure 2: Increase in $t_{u}$ (left) and increase in $F_{u}$ (right)

we find that more competition upstream leaves more profits for input buyers and hence encourages market entry downstream.

We now turn to the competitive conditions of the downstream market.

\section{Proposition 3}

(i) The equilibrium number of downstream firms is increasing in $t_{d}$ and decreasing in $F_{d}$.

(ii) The equilibrium number of upstream firms is increasing in $t_{d}$. There exists an $\bar{F}_{d}$, such that the equilibrium number of upstream firms is increasing in $F_{d}$ if $F_{d}<\bar{F}_{d}$, and decreasing in $F_{d}$ if $F_{d}>\bar{F}_{d}$.

Proof: See Appendix B.

Again, the direct effects of changes in $t_{d}$ and $F_{d}$ on the number of downstream firms are straightforward.

But, as can be seen from (4), an increase in $t_{d}$, i.e. a lower degree of competition in the downstream market, results in upstream firms increasing their prices. If competition in the downstream market is less fierce, an upstream firm can charge a higher price without losing much demand because the disadvantage for a downstream firm that buys from this upstream firm is less severe This results in higher upstream profits and so leads to more entry upstream. This direct price effect dominates any countervailing effect that the resulting increase of $n^{\star}$ could have on $m^{\star}$. The increase in $m^{\star}$, on the other hand, reinforces entry in the downstream market, as can be seen on the left hand side of Figure 3. This result shows that the level of competition in the downstream market, as captured 

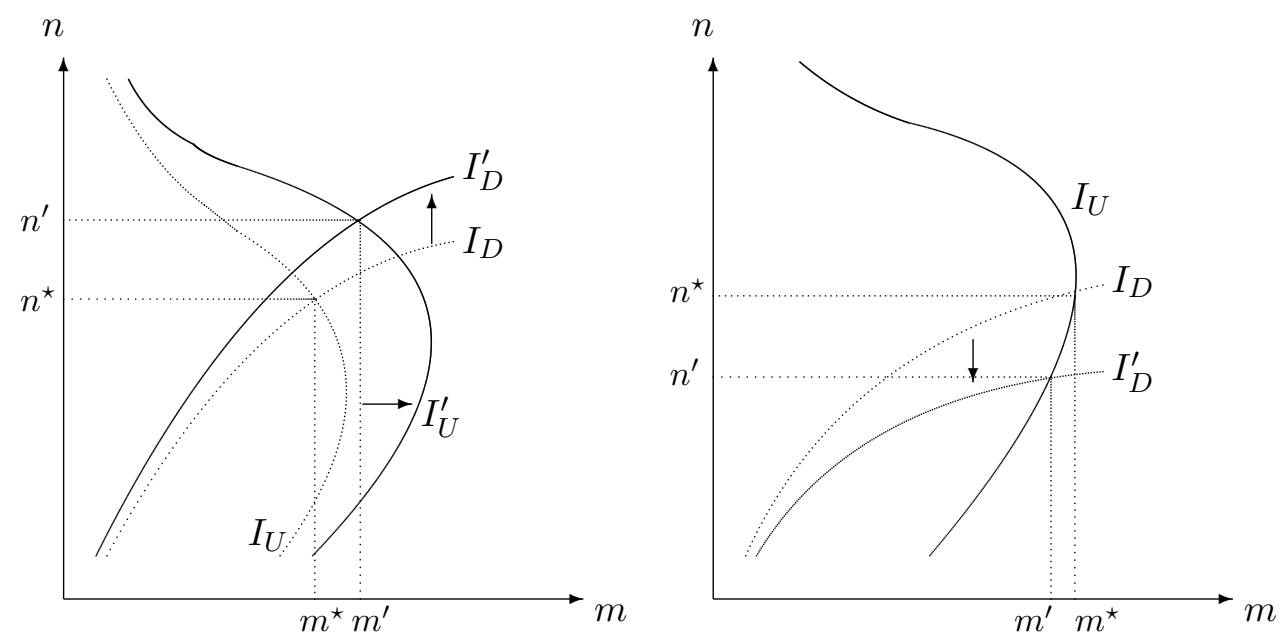

Figure 3: Increase in $t_{d}$ (left) and increase in $F_{d}$ (right)

by the transportation cost parameter, determines the overall profitability of the two tier market structure and thus affects both markets in a similar way. In contrast, as we have seen above, the level of upstream competition affects mainly the distribution of overall profits between upstream and downstream markets.

Consider finally the set-up costs in the downstream market. If $F_{d}$ increases, the number of downstream firms decreases, but, as shown in the last section, this can have either a positive or a negative impact on $m^{\star}$, depending on the number of downstream firms. The right hand side of Figure 3 displays an increase in $F_{d}$ which results in a downward shift of the $I_{D}$-curve. In the figure, the intersection occurs in the increasing part of the $I_{U}$-curve, and so $m^{\star}$ decreases as a result of $F_{d}$ increasing.

At first glance, it may seem intuitive that upstream profits decrease if the number of downstream firms gets larger because competition downstream becomes fiercer. However, as Proposition 3 indicates, this intuition is not always right. The mere fact that the number of potential buyers is larger has a positive effect on upstream profits and so may encourage upstream market entry.

\subsection{Welfare Effects of Downstream Competition}

Most economic models analyze only the downstream market. Thus, the policy implications derived from these models do not consider feedback effects that these policies may have via higher levels in the production chain. Neglecting this interaction might not be a problem per se if the feedback effects 
are small. It is therefore of interest to find out if, first, the implications of a change in downstream competition are over- or undervalued when ignoring the upstream market, and, second, under which conditions a possible misjudgement is particularly large.

To foster competition, policy makers can control two variables. They can decrease entry barriers, for example by reducing red tape for starting new businesses or by making access to the home market easier for foreign firms. In our model, this corresponds to a decrease in firms' set-up costs, $F_{u}$ or $F_{d}$. Another possibility is to increase the degree of competition directly, e.g. by the introduction of standardization measures making it easier for consumers to compare products, or by investing in infrastructure that decreases transport or communication costs. This corresponds to a decrease in $t_{d}$ or $t_{u} \cdot{ }^{25}$ In this section we restrict attention to downstream competition, $t_{d}$ and $F_{d}$.

Since profits are zero in equilibrium, welfare and consumer surplus coincide. ${ }^{26}$ Let $a$ denote a consumer's gross utility from consuming the good. Then welfare can be written as

$$
W F=a-p^{\star}-\frac{t_{d}}{12\left(n^{\star}\right)^{2}}=a-\frac{t_{d}\left(2\left(m^{\star}\right)^{3} t_{d}+t_{u}\left(n^{\star}\right)^{3}\left(3 m^{\star}-1\right)\right)}{\left(n^{\star}\right)^{2}\left(2\left(m^{\star}\right)^{3} t_{d}+t_{u}\left(n^{\star}\right)^{3}\left(m^{\star}-1\right)\right)}-\frac{t_{d}}{12\left(n^{\star}\right)^{2}} .
$$

The next proposition states when the welfare effects from reducing $t_{d}$ and $F_{d}$ are over - or underestimated.

\section{Proposition 4}

When ignoring the interaction with the upstream market,

(i) the positive welfare effect of decreasing $t_{d}$ is always overestimated.

(ii) the positive welfare effect of decreasing $F_{d}$ can be either over-or underestimated. There exists an $\bar{F}_{d}$ such that for $F_{d}<\bar{F}_{d}$ it is overestimated, while for $F_{d}>\bar{F}_{d}$ it is underestimated.

Proof: See Appendix B.

Of course, both a decrease in $t_{d}$ and a decrease in $F_{d}$ have positive welfare effects, because of lower transportation costs and lower prices. However, these positive effects are mitigated if stronger competition downstream reduces market entry upstream and hence has a negative feedback effect on market entry downstream. Thus, the results in Proposition 4 are easy to understand in light of

\footnotetext{
${ }^{25} t_{d}$ and $t_{u}$ were formally introduced as preference or technology parameters. To think about a decrease in $t_{d}$ or $t_{u}$ as the result of deregulation, one can interpret the specification of consumer utility or downstream firms' production functions as reduced form. There, $t_{d}$ reflects higher product substitutability while $t_{u}$ reflects higher input substitutability. For a similar exercise and a discussion of this interpretation, see Blanchard and Giavazzi (2003).

${ }^{26}$ Policy makers are often concerned only with consumer welfare instead of total welfare. Since both measures are identical here, our results apply to this case as well.
} 
Propositions 2 and 3 . For example, lowering $t_{d}$ induces upstream firms to exit the market. So the positive welfare effect of fostering downstream competition is overestimated when ignoring the upstream market. On the other hand, if more market entry downstream encourages market entry upstream, as is the case when the number of downstream firms is sufficiently small $\left(F_{d}>\bar{F}_{d}\right)$, the upstream market reinforces the positive welfare effect. In this case, this welfare effect is underestimated when ignoring the upstream market.

It is interesting to explore under which conditions the overestimation effect from a change in $t_{d}$ is particularly high.

\section{Corollary 1}

The magnitude of the overestimation resulting from a change in $t_{d}$ is increasing in $t_{u}$ and decreasing in $t_{d}$ and $m^{\star}$.

Proof: See Appendix B.

The results with respect to $m^{\star}$ and $t_{u}$ are intuitive. If competition in the upstream market is low, which means that either $m^{\star}$ is small or that $t_{u}$ is high, the upstream market matters a lot for the competitive conditions in the downstream market. Thus, the mistake made when ignoring the upstream market is large. On the other hand, this mistake is also large when $t_{d}$ is small. The reason is that if downstream competition is fierce, a change in the upstream price is passed on to the downstream price almost one-to-one.

The analysis shows that there is generally a problem when looking only at the downstream markets and ignoring previous layers in the production chain. Especially if the upstream market exhibits a low degree of competition, the feedback effects on the downstream market are large.

\subsection{Upstream vs. Downstream Deregulation}

Of course, there is no reason why a policy maker should restrict attention to intervening in the output market if she wants to foster competition. In this section, we analyze in which market deregulation is more effective in order to spur competition and increase welfare. The answer seems straightforward if upstream and downstream markets are very asymmetric, one being very competitive while the other is not very competitive. And indeed, it can be shown in our model that, in such cases, it is more effective to intervene in the less competitive market. The answer is no longer obvious if both markets are similarly competitive.

We first look at the case of a decrease in set-up costs and compare the welfare effect of reducing 
$F_{d}$ with the effect of reducing $F_{u}$, namely $\left|\partial W F / \partial F_{d}\right|-\left|\partial W F / \partial F_{u}\right|$. As mentioned above, we focus on the most interesting case, namely when market conditions upstream and downstream are similar. This means that $t_{d} \approx t_{u}$ and $n^{\star} \approx m^{\star} \cdot{ }^{27}$

\section{Proposition 5}

If competitive conditions in both markets are equal, $t_{d}=t_{u}$ and $n^{\star}=m^{\star}$, then

$$
\left|\frac{\partial W F}{\partial F_{d}}\right|-\left|\frac{\partial W F}{\partial F_{u}}\right|>0
$$

if and only if $m^{\star}<\tilde{m}$, where $\tilde{m}$ is implicitly defined by

$$
429(\tilde{m})^{2}-37(\tilde{m})^{3}-555 \tilde{m}-157=0 .
$$

Proof See Appendix B.

If the competitive conditions are exactly equal, $\tilde{m}(\approx 10.62)$ is the number of firms in each market below which deregulation in the downstream market is more effective than in the upstream market. Yet, by continuity arguments the result also holds when the competitive conditions are similar in the two markets but are not exactly equal.

The intuition behind this result is the following. From Section 3 we know that if the number of downstream firms is small, entry in the downstream market induces more firms to enter upstream. This, in turn, induces more downstream firms to enter. Thus, the upstream market reinforces the positive effect on the downstream market if the overall number of firms is small. The opposite is true if there is a large number of downstream firms because inducing more entry downstream has a negative impact on the number of upstream firms. As a consequence, the positive effect on the downstream market is diminished and so it is more effective to spur entry in the upstream market if the number of firms is large.

Now we turn to the case of a change in the transport costs. As in the case of set-up costs, if competitive conditions in the two markets are very asymmetric, it is easy to show that decreasing transport cost in that market where competition is less fierce is more effective. Now suppose, as before, that market conditions are similar, $t_{d} \approx t_{u}$ and $n^{\star} \approx m^{\star}$.

\footnotetext{
${ }^{27}$ It is easy to show that if the number of downstream firms is much higher than the number of upstream firms, deregulation upstream is more effective than deregulation downstream independent of the degree of competition. Also, if the transport costs downstream are much lower than those upstream, lowering entry barriers upstream has a larger impact on welfare.
} 


\section{Proposition 6}

If competitive conditions in the two markets are equal,

$$
\left|\frac{\partial W F}{\partial t_{d}}\right|-\left|\frac{\partial W F}{\partial t_{u}}\right|>0
$$

if and only if $m^{\star}<m^{\prime}$, where $m^{\prime}$ is implicitly defined by

$$
205\left(m^{\prime}\right)^{2}-37\left(m^{\prime}\right)^{3}-226 m^{\prime}+468=0 .
$$

Proof See Appendix B.

This proposition shows that increasing competition directly through a change in the transport costs in the downstream market is more effective if the overall number of firms is small (i.e. $m^{\star}<m^{\prime} \approx$ 4.82). ${ }^{28}$ The result closely resembles that of Proposition 5 but the intuition is different. If upstream transportation costs decrease, input prices decrease and this decrease is passed on to downstream prices to some extent. However, this extent depends on the competitive conditions downstream. If the number of downstream firms is small, the downstream margin is still high and so downstream prices do not fall much. Thus, in this case it is more effective to spur competition downstream, since this has a direct effect on downstream prices. On the other hand, with a large number of firms in both markets, a decrease in the upstream prices via a reduction of $t_{u}$ is passed down to a large extent and so deregulation in the upstream market is more effective. ${ }^{29}$

In summary, deregulation in the downstream market tends to be more effective than in the upstream market if the overall number of firms is small and thus if consumer surplus is relatively low. This coincides with the case where the positive welfare effects of decreasing entry barriers in the output market tend to be underestimated if the interaction with the upstream market is ignored. ${ }^{30}$

\footnotetext{
${ }^{28}$ As before, due to continuity arguments, the result also holds if market conditions are not exactly equal but are similar.

${ }^{29}$ Note that $\tilde{m}>m^{\prime}$. So, if market conditions are exactly equal, the superiority of downstream deregulation compared to upstream deregulation holds for more parameter constellations when deregulation is induced via reducing entry barriers than via increasing the degree of competition directly. This is the case because, for a small number of firms, decreasing $F_{d}$ has a positive effect on the number of downstream and upstream firms. On the contrary, a reduction in $t_{d}$ decreases both downstream and upstream prices directly but induces firms to exit the market and this has a negative effect on consumer welfare which is larger the lower the overall number of firms is.

${ }^{30} \mathrm{~A}$ question we have not addressed here is about the socially optimal number of firms. It is well known from the papers of Salop (1979) and especially Mankiw and Whinston (1986) that there is insufficient entry when looking only at the downstream market because of the business stealing effect. The result is less clear when explicitly considering the interaction between upstream and downstream market. Perhaps surprisingly, we find that in our model the result of excessive entry still holds for both markets. (The proof of this result is available at http://www.en.compecon.vwl.lmu.de/research/download/.) This result can be contrasted with recent findings by Ghosh and Morita (2007) who show in a model of Cournot competition that insufficient entry may occur in both markets because the additional surplus that an entering firm generates is partly captured by firms in the adjacent market. Our findings show that this result is not innocuous to the mode of competition and depends on the exact structure of vertical relationships.
} 


\subsection{Examples of Deregulation}

We discuss three examples of deregulation of either downstream or upstream markets from different industries and countries and confront the observations with the results of the model.

\subsubsection{Downstream Deregulation}

\section{The market for natural gas in the US}

Deregulation of the natural gas market in the U.S. began in 1978 with the Natural Gas Act, but was not complete until 1992 with Federal Energy Regulatory Commission (FERC) order No. 636 (OECD, 2000, p.328). Before order No. 636, retail distribution of natural gas was highly regulated by the states. In most states, consumers could buy gas only from their Local Distribution Company (LDC) at state-regulated prices. Order No. 636, among other things, set the ground for liberalizing the retail business and facilitating entry. In the following years, more than 20 states implemented this order on a state level, and new gas brokers and resellers entered the retail market. These new sellers buy the transmission of gas from intrastate pipelines and LDCs and sell the gas to final customers. ${ }^{31}$ Although especially commercial and industrial consumers switched to new marketers, the number of these resellers is still limited, and, in almost all states, a few retailers control most of the market. Thus, downstream markets are more competitive now than they used to be, but retailing firms still enjoy considerable market power. Indeed, consumer prices for natural gas, that had increased a lot before 1992, stabilized until 1999 and began to rise after 2000, but at a much smaller rate than those for oil.

What were the consequences of this downstream entry on the upstream market, the intrastate pipelines? $^{32}$ Before deregulation, in regions with low demand intrastate pipelines were monopolies, and even in agglomeration areas only few pipeline companies were present. After deregulation, several companies built new pipelines, especially in regions with high gas demand. ${ }^{33}$ So downstream market entry triggered moderate entry in at least some of the upstream markets as well. ${ }^{34}$

\footnotetext{
${ }^{31}$ The prices that LDCs charge for transmission are required to be non-discriminatory and are regulated by the state public utility commission.

${ }^{32}$ The relevant upstream market affected by downstream deregulation are first and foremost intrastate pipelines because the prices of interstate pipelines are still FERC-regulated (see e.g. McAfee and Reny (2007)). Moreover, on the production side there are several thousand natural gas producers, among them over 20 major firms (Doane and Spulber, 1994). As a consequence, downstream deregulation had little effect on prices in these markets.

${ }^{33}$ During the last decade, an average of around 2500 new pipeline miles per year were built or already approved, most of them intrastate pipelines. This is not due to increased gas production, which rose by only $2 \%$ between 1998 and 2004 (Energy Information Administration, 2006).

${ }^{34}$ For example, in 1997 Kern River Transmission Company was building a new pipeline to serve industrial consumers
} 


\section{The electricity market in Germany}

Until 1998, the German electricity market was regulated. In each region, there was one public electricity utility that sold electricity to final consumers. Thus, consumers could not choose from which company to buy electricity. In April 1998, the electricity retailing market was liberalized and, essentially, free market entry was allowed. Since then, more then 200 new companies entered the market, and a consumer in almost every region of Germany can now choose between around 25 firms to buy electricity from. ${ }^{35}$ Indeed, many consumers switched electricity suppliers or obtained lower rates from their old supplier. Electricity prices dropped steadily from 1998 on, and in 2001 they were $20 \%$ below the level of 1998 .

In the upstream market, until 2000 there were eight electricity producing companies, who also owned the high-voltage transmission grid. These companies generated more than $80 \%$ of the electricity consumption in Germany. But the downstream liberalization triggered a merger wave among the eight main electricity producers. By 2002, only four large generating companies were left, who now produce more than $90 \%$ of the electricity. ${ }^{36}$ From 2001 on, the downward trend in end user prices was reversed and prices began to increase, reaching top levels in 2007. Certainly, price increases of raw materials like coal and gas contributed to this price development, but, arguably, the concentration process in the upstream market had its share in this development. This example illustrates the result obtained in Section 4.2., i.e. the positive effect of downstream deregulation is overestimated when entry of new downstream firms induces upstream firms to merge, countering the positive welfare effect of increased downstream competition.

\section{Comparison with the model}

In both examples, the natural gas market in the U.S. and the electricity market in Germany, deregulation triggered entry in the downstream market, but the effects on the upstream market were very different. In the U.S., moderate upstream entry occurred while in Germany upstream firms merged. The U.S. example is thus consistent with the lower part of the iso-profit curve $I_{U}$ in Figure 3 , where a decrease in $F_{d}$ leads to an increase in $m^{\star}$, for $n^{\star}$ low. In the U.S. gas market, the number of entering downstream firms was relatively low and these firms still had market power. As a result, upstream

in the Salt Like City area thereby competing with Questar Corporation who was acting in this area a monopolist. Recently, the Railroad Commission of Texas reported that the intrastate pipeline system in Texas is considered to be competitive (http://www.rrc.state.tx.us/news-releases/2006/041106.html).

${ }^{35}$ Public utilities still own the net for low-voltage transmission in the respective region, but were forced to grant third party access at regulated fees.

${ }^{36}$ These companies are EnBW AG, E.ON. Energie AG, RWE AG, and Vattenfall. 
companies experienced downstream entry predominantly as an increase in the number of potential buyers. The German case is instead consistent with the upper part of the iso-profit curve $I_{U}$ in Figure 3, where a decrease in $F_{d}$ reduces $m^{\star}$, for a large $n^{\star}$. In the German electricity market, entry of electricity marketers was enormous, leading to fierce price competition in the electricity market. This negative price effect dominated the positive effect of more potential buyers for upstream firms and induced them to merge, thereby reversing the initial price decrease.

\subsubsection{Upstream Deregulation}

\section{The market for ready-mixed concrete in India}

A striking example for the effects of upstream deregulation on the downstream market is the development of the market for ready-mixed concrete (RMC) in India, after deregulation of the cement market. ${ }^{37}$ Before 1982, the cement industry in India was fully and, until 1989, it was partially regulated, because the Indian government considered cement an essential commodity and regulated prices and distribution. Since 1989, the market is fully deregulated. Between 1989 and 2001, a large number of national and foreign firms entered the cement market. Due to this entry, upstream competition became fiercer and cement prices started to fall, from Rp.180 per bag in 1999 to Rp.80-90 in 2001.

Before 2000, the market for RMC barely existed in India, even though in fully developed countries around $70 \%$ of cement is used to produce RMC. One of the reasons why the market for RMC did not develop was the lack of reliable material, form work, good construction practices, portable water and a skilled workforce. Moreover, the government inflicted an excise duty of $20 \%$ on commercial RMC. Due to these obstacles, before 1999 most RMC manufacturers failed. ${ }^{38}$ But when cement prices came down after sufficient entry in the upstream market, the market for RMC started to take off, with growth rates of $30-40 \%$ and even higher growth rates expected in the future. ${ }^{39}$ Several new firms entered the RMC market and RMC became an established construction material. Arguably, the RMC market emerged only when upstream competition was intensive enough. This is consistent with the results of our model that upstream entry and fiercer competition has a positive effect on the downstream market.

\footnotetext{
${ }^{37}$ Cement is the most important input to produce RMC.

${ }^{38}$ In their study on the RMC market in India, Gordon and Kshemendranath (1999) write: "For acceptability of RMC in the market, it is necessary to change existing construction practices. (...) This will be a very long and continuous process to which there appears no end."

${ }^{39}$ In 2005 the number of operating plants was already 125 compared to around 20 in 1999. Moreover, Building Products L\&T plans to set up 100 new plants during the next five years. See http://www.projectsmonitor.com/MonthlyArchive. asp?Month=6\&Year=2005.
} 


\section{$5 \quad$ Vertical Restraints}

So far we restricted the contract of an upstream firm to be linear. Yet, in several industries, upstream firms engage in different forms of vertical restraints. In this section, we analyze two of them, namely two-part tariffs and resale price maintenance (RPM). We first show that the model can be solved by the same technique as used for the case of linear prices and that there is a unique equilibrium in both cases. Afterwards, we compare the outcome of the different regimes with each other and with the outcome in the case of linear prices. This allows us to draw conclusions under which conditions different forms of vertical restraints are pro - or anticompetitive. In this respect, our analysis goes beyond previous papers that take the market structure as given. In contrast, our analysis takes into account how the number of firms changes once vertical restraints are introduced and so it allows for a more complete picture of the advantages and drawbacks of vertical restraints.

\section{$5.1 \quad$ Two-Part Tariffs}

In contrast to the case of linear prices, under a two-part tariff regime an upstream firm $i$ now charges a per unit price $r_{i}$ and a fixed fee $T_{i}, i \in\{1, \ldots, m\}$, where $T_{i}$ is independent of the quantity that a downstream buys. The game structure, the information structure concerning locations, and the time line are the same as in the case of linear prices. To make the problem interesting, we assume, as in the case of linear prices, that it is profitable for at least two firms to enter each market. ${ }^{40}$

As a consequence, the third stage of the game plays out exactly as in the case of linear prices, given the upstream price vector $\mathbf{r} .{ }^{41}$ The profit function of upstream firm $i$ can then be written as

$$
E\left[P_{i}\left(r_{i}, r_{-i}, T_{i}, T_{-i}\right)\right]=\left(r_{i} y_{i}(\mathbf{r})+T_{i}\right) n q_{i}(\mathbf{r}),
$$

where $y_{i}(\mathbf{r})$ and $q_{i}(\mathbf{r})$ are solved for in the third stage. Solving the game in the same way as in Section 3 yields the following equilibrium. ${ }^{42}$

\section{Proposition 7}

There exists a unique symmetric subgame perfect equilibrium of the three stage game with two-part

\footnotetext{
${ }^{40}$ In the following we only explain briefly how to derive the equilibrium because the technique is similar to the linear-pricing regime.

${ }^{41}$ As before, we assume that it is indeed optimal for a downstream to buy a positive quantity after entering, independent of its upstream location.

${ }^{42}$ The proof proceeds along similar lines as the proof of Proposition 1. It is available at http://www.en.compecon.vwl.lmu.de/research/download/.
} 
tariffs. In this equilibrium, the number of entering upstream and downstream firms, $n_{t p}^{\star}$ and $m_{t p}^{\star}$, is implicitly defined by

$$
\frac{t_{d}}{\left(n_{t p}^{\star}\right)^{3}}-\frac{13 t_{u}}{12\left(m_{t p}^{\star}\right)^{2}}=F_{d} \quad \text { and } \quad \frac{t_{u} n_{t p}^{\star}}{\left(m_{t p}^{\star}\right)^{3}}=F_{u} .
$$

Upstream firms charge a per unit price of $r_{t p}^{\star}$ and a fixed fee of $T_{t p}^{\star}$ while downstream firms charge a price of $p_{t p}^{\star}$, where

$$
r_{t p}^{\star}=0, \quad T_{t p}^{\star}=\frac{t_{u}}{\left(m_{t p}^{\star}\right)^{2}}, \quad \text { and } \quad p_{t p}^{\star}=\frac{t_{d}}{\left(n_{t p}^{\star}\right)^{2}}
$$

With two-part tariffs, the iso-profit curves of upstream and downstream firms are determined by (11). For an upstream firm the slope of its iso-profit curve is given by

$$
\frac{\partial m}{\partial n}=\frac{m}{3 n}>0
$$

while for a downstream firm it is given by

$$
\frac{\partial n}{\partial m}=\frac{13 t_{u} n^{4}}{18 t_{d} m^{3}}>0
$$

Both iso-profit curves are increasing, i.e. a larger number of upstream firms triggers more entry in the downstream market and vice versa. The reason for the first result is similar to that under linear prices. More upstream firms reduce the expected transport costs of downstream firms and now additionally lead to a lower fixed fee due to increased competition. On the other hand, in contrast to the case of linear prices a larger number of downstream firms increases the profit of an upstream firm under two-part tariffs. The intuition here is that upstream firms set the per-unit price equal to marginal costs and only make a profit via the fixed fee. Thus, although competition downstream increases in $n$, this affects neither the per-unit price nor the fixed fee. As a consequence, a larger number of downstream firms only increases the probability of collecting the fixed fee since more potential buyers are present. Thus, upstream profits increase. ${ }^{43}$ The equilibrium is illustrated in Figure 4.

We can now compare the equilibrium number of firms under two-part tariffs with that under linear prices.

\footnotetext{
${ }^{43}$ The question may arise if downstream firms can potentially be expropriated via the fixed fee. Once a downstream firm has entered the market, its set-up cost is sunk, and so it would also accept paying a fixed fee up to its expected operating profit, thereby rendering entry in the first stage not optimal. Yet this is not the case in equilibrium. In the first stage, downstream firms foresee the amount of the fixed fee in equilibrium which is bounded by upstream competition, and thus enter accordingly.
} 


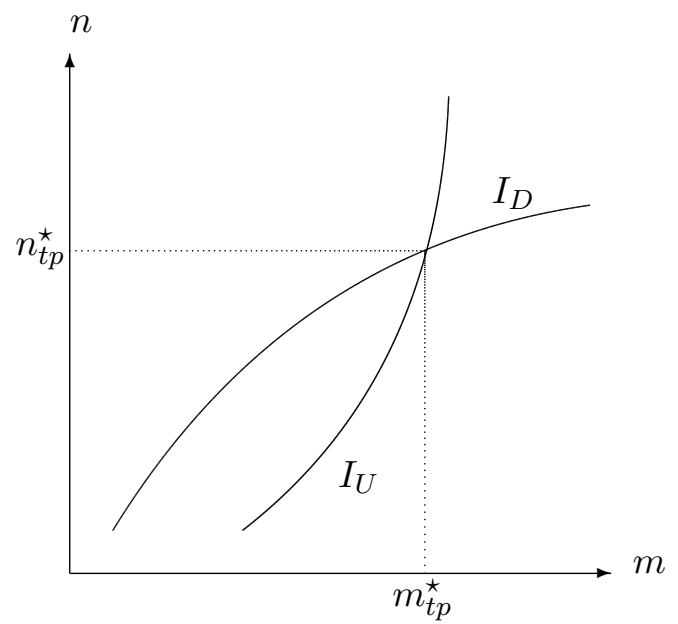

Figure 4: Equilibrium with two-part tariffs

\section{Proposition 8}

A comparison between the equilibrium market structure under two-part tariffs and the one under linear prices yields

$$
n^{\star}>n_{t p}^{\star} \quad \text { and } \quad m^{\star}<m_{t p}^{\star}
$$

Proof: See Appendix C.

Under linear pricing, the degree of downstream competition crosses over to the upstream market. Thus, both the degree of upstream and downstream competition confine the upstream prices. By contrast, under the two-part tariff regime, where upstream firms get their revenue only from the fixed fee, only the degree of upstream competition matters. ${ }^{44}$ As a consequence, $m_{t p}^{\star}>m^{\star}$. Since upstream firms can extract a higher revenue from downstream firms under two-part pricing via the fixed fee, profits of downstream firms are lower, i.e. $n_{t p}^{\star}<n^{\star}$.

We can now compare welfare under two-part tariffs with welfare under linear prices. Under two-part tariffs welfare (and consumer rent) are given by

$$
W F_{t p}=a-\frac{13 t_{d}}{12\left(n_{t p}^{\star}\right)^{2}}
$$

while under linear prices they are given by

$$
W F=a-\frac{t_{d}\left(26\left(m^{\star}\right)^{3} t_{d}+t_{u}\left(n^{\star}\right)^{3}\left(37 m^{\star}-13\right)\right)}{12\left(n^{\star}\right)^{2}\left(2\left(m^{\star}\right)^{3} t_{d}+t_{u}\left(n^{\star}\right)^{3}\left(m^{\star}-1\right)\right)} .
$$

\footnotetext{
${ }^{44}$ To be more precise, $t_{d}$ only matters indirectly via $n_{t p}^{\star}$ but this indirect effect is also present under linear prices.
} 
It is often argued that two-part tariffs on the manufacturer side are welfare enhancing because double marginalization is avoided. The argument is that double marginalization leads to higher prices and hence lower welfare. ${ }^{45}$ However, the next proposition shows that this is not always the case:

\section{Proposition 9}

Welfare under linear prices can either be higher or lower than under two-part tariffs. In particular, it is higher if

$$
n_{t p}^{\star} \leq n^{\star}\left(\frac{\sqrt{13}\left(\sqrt{3} t_{d}\left(t_{u} n^{\star}\right)^{(3 / 2)}+6 t_{u}\left(t_{d}-F_{d}\left(n^{\star}\right)^{3}\right)\left(n^{\star} \sqrt{3 t_{u} n^{\star}}-6 \sqrt{t_{d}-F_{d}\left(n^{\star}\right)^{3}}\right)\right)}{\sqrt{3} t_{d}\left(t_{u} n^{\star}\right)^{(3 / 2)}+6 t_{u}\left(t_{d}-F_{d}\left(n^{\star}\right)^{3}\right)\left(37 n^{\star} \sqrt{3 t_{u} n^{\star}}-78 \sqrt{t_{d}-F_{d}\left(n^{\star}\right)^{3}}\right)}\right)^{(1 / 2)}
$$

where $n^{\star}$ and $n_{t p}^{\star}$ are implicitly defined by

$$
\frac{72 t_{u} t_{d}\left(t_{d}-F_{d}\left(n^{\star}\right)^{3}\right)^{(3 / 2)}}{\left(n^{\star}\right)^{2}\left(6 t_{u} n^{\star} \sqrt{3 t_{u} n^{\star}}\left(t_{d}-F_{d}\left(n^{\star}\right)^{3}\right)-36 t_{u}\left(t_{d}-F_{d}\left(n^{\star}\right)^{3}\right)^{(3 / 2)}+t_{d} \sqrt{3}\left(t_{u} n^{\star}\right)^{(3 / 2)}\right)}=F_{u}
$$

and

$$
\frac{24 \sqrt{39}\left(t_{d}-F_{d}\left(n_{t p}^{\star}\right)^{3}\right)^{(3 / 2)}}{169 \sqrt{t_{u}}\left(n_{t p}^{\star}\right)^{(7 / 2)}}=F_{u}
$$

Proof: See Appendix C.

There are two opposing effects that arise when comparing the welfare effects. In contrast to linear pricing, no double marginalization arises under two-part tariffs. On the other hand, downstream profits are higher under linear prices and so more downstream firms enter, resulting in increased competition and lower transport costs. The proposition shows that, if the difference in the number of downstream firms is sufficiently high, welfare under linear prices is higher. ${ }^{46}$

It is of interest to know under which market conditions linear pricing is favored from a welfare point of view as compared to two-part tariffs. For this purpose, we look at a change in the upstream market conditions (via changing $t_{u}$ and $F_{u}$ ) and in the downstream market conditions (via changing $t_{d}$ and $\left.F_{d}\right)$ in turn to analyze how they affect the comparison between the two regimes.

\footnotetext{
${ }^{45}$ Note that in our model there is no negative quantity effect arising from double marginalization. However, due to the fact that market entry leads to zero profits and hence welfare decreases in output prices, the negative implications of the double marginalization problem are captured in our model as well.

${ }^{46}$ In a model with an upstream monopolist and a perfectly competitive downstream industry, Ordover and Panzar (1982) show that linear prices can be welfare superior compared to two-part tariffs. Yet, in their model, due to perfect downstream competition double marginalization does not arise. In contrast, we consider an oligopoly upstream and downstream with free entry and show that linear pricing can be welfare superior even if double marginalization is an issue.
} 


\section{Upstream Market Conditions}

We start by analyzing a change in $t_{u}$ or $F_{u}$. Prices and transport costs for downstream firms rise if $t_{u}$ and $F_{u}$ increase. As a consequence, the number of downstream firms decreases in both regimes. Yet, this decrease is larger under two-part tariffs. The reason is that the amount of the fixed fee in equilibrium is increasing in $t_{u}$ and $F_{u}$ (via a decrease in $m_{t p}^{\star}$ ) and downstream firms can not recoup this increase via output prices. Instead, under linear pricing, downstream firms face higher input prices but can pass them on to some extent via higher final good prices. This implies that the problem of double marginalization increases as well, but overall the decrease in the number of downstream firms is more detrimental to welfare. As a consequence, welfare under linear prices is higher than under two-part tariffs if $t_{u}$ or $F_{u}$ is large and vice versa. Figure 5 illustrates this result (on the left hand side the parameter values are $a=0.1, t_{d}=1, F_{u}=0.001$ and $F_{d}=0.001^{47}$ while on the right hand side, they are set at $a=0.2, t_{u}=1, t_{d}=1$ and $F_{d}=0.001$ ).

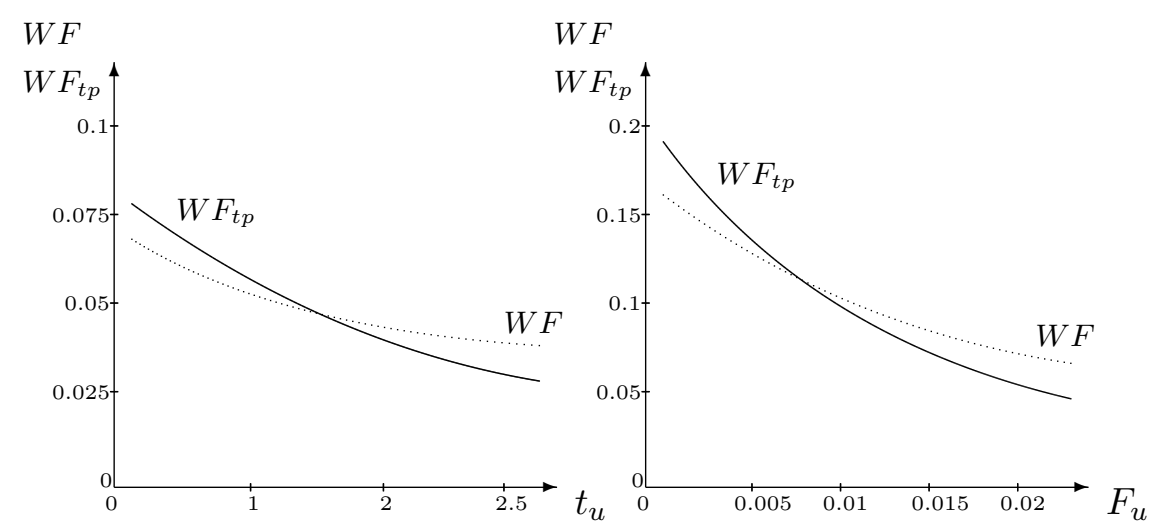

Figure 5: Change in $W F$ and $W F_{t p}$ with $t_{u}$ (left) and with $F_{u}$ (right).

\section{Downstream Market Conditions}

We now look at the effects of a change in $t_{d}$ and $F_{d}$. It is evident that a change in $t_{d}$ or $F_{d}$ has no direct effect on upstream prices in the two-part tariff regime (only an indirect one via a change in $n_{t p}^{\star}$ ). This is different in the linear pricing regime where, as we discussed in Section 4, downstream competition carries over to the upstream market. As $t_{d}$ or $F_{d}$ increase, double marginalization becomes more pronounced under linear prices. As $t_{d}$ gets larger, the number of upstream and downstream firms increase in both regimes but the force of this effect is similar. As $F_{d}$ increases, $n_{t p}^{\star}$ and $m_{t p}^{\star}$ decrease under two-part tariffs while under linear pricing $n^{\star}$ decreases and $m^{\star}$ may rise or fall. Still, the

\footnotetext{
${ }^{47}$ One can check that with these parameters, independent of its upstream location, a downstream firm is active after entering as long as $t_{u}<5.6$.
} 
effect of pronounced double marginalization dominates the potential increase in $m^{\star}$ as $F_{d}$ rises. As a consequence, if $t_{d}$ or $F_{d}$ is relatively small, welfare is larger in the linear pricing regime because there is almost no double marginalization and the number of downstream firms is larger, while it is smaller if $t_{d}$ or $F_{d}$ is relatively large. The left hand side of Figure 6 plots the change of $W F_{l p}$ and $W F_{t p t}$ in $t_{d}$ (here $a=0.1, t_{u}=1, F_{u}=0.001$ and $F_{d}=0.001$ ) while the right hand side plots the change in $F_{d}$ (here $a=0.1, t_{u}=1, t_{d}=1$ and $F_{u}=0.001$ ).

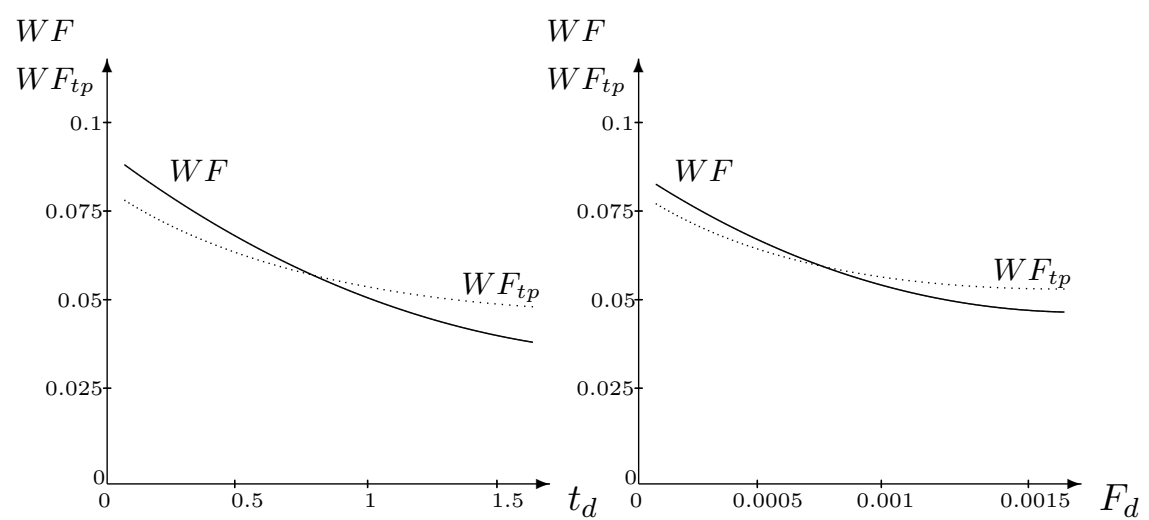

Figure 6: Change in $W F$ and $W F_{t p}$ with $t_{d}$ (left) and with $F_{d}$ (right).

Summing up, this section has shown that the problem of double marginalization is especially severe if downstream competition is low, either because $t_{d}$ and/or $F_{d}$ is/are large. In such markets, welfare under two-part tariffs is higher than under linear pricing. On the contrary, if upstream competition is low (high $t_{u}$ and/or high $F_{u}$ ), two-part tariffs reduce entry in the downstream market to a large extent, thereby making this market less competitive. In such cases, two-part tariffs are likely to reduce welfare. Overall, the analysis shows that the effects of two-part tariffs on market entry can be large, and so a policy that conditions only on double marginalization might be misguided.

\subsection{Resale Price Maintenance}

Resale Price Maintenance (RPM) is the practice of upstream firms fixing the selling price of the downstream firm. ${ }^{48}$ As already pointed out in the introduction, RPM is prohibited in many countries. Yet, the theoretical literature does not give a clear view on RPM. ${ }^{49}$ In particular, as Rey and Verge

\footnotetext{
${ }^{48}$ At first glance, RPM might not seem to be a possible contract in our model since downstream firms further process an upstream firm's input good. Yet, for example, our model fits well to markets for tools and standard parts. These goods are often sold in do-it-yourself stores where each store buys a particular tool or standard part from just one manufacturer since there is no point in offering diversity. In industries of this kind, the manufacturers can easily engage in RPM, since the service provided by downstream firms is not to change the input but to retail it to consumers.

${ }^{49}$ See, for example, the recent papers by Dobson and Waterson (2006) or Rey and Verge (2004).
} 
(2004) point out, it is not clear that RPM has a larger negative impact on consumer welfare than other vertical restraints, like two-part tariffs. It is thus interesting to compare these two regimes in our model of free entry and varying degrees of competition..$^{50}$

Under RPM, the only decision a downstream firms makes is to choose its respective input supplier. Upstream firms have pricing power over the input and output prices. After solving for the equilibrium, an immediate result is that the equilibrium contains double marginalization. This is intuitive: upstream firms can only make profits by charging a price above marginal costs while they can attract potential buyers only by leaving them a profit margin as well.

We can then compare the welfare effects of RPM with those under linear pricing and under twopart tariffs. As in the case of linear pricing, double marginalization arises under RPM as well, but it is less severe. The reason is that the final good prices are controlled by the upstream firms who have a lower interest in maximizing downstream profits than the downstream firms themselves. On the other hand, since downstream firms have no market power under RPM, fewer of them enter. It can be shown that either of the two effects might dominate and welfare under RPM can be higher or lower than under linear pricing.

The results concerning the comparison of RPM with two-part tariffs are more interesting. Here we find that welfare under two-part tariffs is unambiguously higher than under RPM. The basic intuition is that downstream prices are lower under two-part tariffs due to the avoidance of double marginalization. Interestingly, the number of upstream and downstream firms is higher under RPM. However, we can show that this effect is only a second order one compared to the higher downstream prices. Loosely speaking, under RPM all competition takes place at the upstream stage and so the second layer of competition is eliminated compared to two-part tariffs. This is always detrimental to welfare.

There are two main conclusions that can be drawn from the analysis of RPM. First, the effect of higher downstream prices compared to two-part tariffs is dominant even when taking free entry into account. Thus, there is some justification for treating RPM as a device for reducing competition and thus prohibiting it. Second, it would not be enough to ban one instrument, e.g. two-part tariffs, if upstream firms substitute it with another, e.g. RPM, that is even more detrimental to welfare. ${ }^{51}$

\footnotetext{
${ }^{50}$ In this section, we only discuss the results under RPM and the comparison with the other regimes. A formal derivation is available at http://www.en.compecon.vwl.lmu.de/research/download/.

${ }^{51}$ For a further discussion of this point, see Rey and Tirole (2007).
} 


\section{Conclusion}

This paper has provided a model of successive oligopolies that allows for endogenous entry and varying degrees of competition in both markets. We showed how the competitive conditions in the two markets influence each other and gave implications for deregulation policies. The model is suitable for analyzing the implications of different forms of bilateral contracting. We restricted attention to two-part tariffs and RPM because of their prominence, but it is also of interest to look at other forms of vertical restraints, e.g. quantity forcing contracts. The model can also provide a framework to study the consequences of vertical mergers, in particular, how the two-tier market structure would evolve if vertical mergers were allowed. However, given the asymmetric nature of firms in this case, such an analysis becomes more intricate.

Another direction for future research is to allow for bargaining between upstream and downstream firms. In our model, only upstream firms have market power over the input price. However, incorporating bargaining between the two sides in this general framework can give new insights into how competition and free entry shape the outside options of each firm and hence the market structure. Since in our model upstream firms make take-it-or-leave-it offers, the resulting upstream price can be seen as an upper bound in any bargaining game. If one allows for more equal bargaining power, it is likely that the upstream price decreases and the number of firms adjusts accordingly. Nevertheless, it seems plausible that our qualitative insights concerning the interplay between the two markets stay unchanged.

Throughout the paper we have restricted attention to analyzing the two tier market structure of an upstream and a downstream market. In principle, the model could be extended to a multi-layer market structure. There is no reason to expect that the main insights of the analysis would change if there were more stages of production. 


\section{Appendix}

\subsection{Appendix A}

\section{Proof of Proposition 1}

In stage three downstream firms simultaneously set final good prices. Each firm knows its own input price but not the input price of its neighboring firms. However, as described in Section 3, each firms knows the expected input price of its rivals. Downstream firms potentially buy at different input prices but are otherwise identical. So, in a symmetric equilibrium, there can at most be $m$ different final good prices. Since firm $j$ 's expectation about the location of its neighbors in the upstream market is the same, we have that $E\left[p_{j-1}\right]=E\left[p_{j+1}\right]=E\left[p_{-j}\right]=\sum_{k=1}^{m} q_{k} p_{k}$, where $p_{k}$ is the price of a downstream firm when it buys from upstream firm $k$. Thus, the expected profit function (net of transport cost and set up cost) of a downstream firm that buys from upstream firm $i$ is given by

$$
E\left[\Pi^{i}\left(p_{i}, r_{i}, p_{-i}\right)\right]=\left(p_{i}-r_{i}\right)\left(\frac{1}{n}+\frac{n\left(\sum_{k=1}^{m} q_{k} p_{k}-p_{i}\right)}{t_{d}}\right), \quad i \in\{1, \ldots, m\} .
$$

Maximizing the last equation with respect to $p_{i}$ gives a reaction function of

$$
p_{i}=\frac{t_{d}+n^{2}\left(r_{i}+\sum_{k=1}^{m} q_{k} p_{k}\right)}{2 n^{2}} .
$$

Multiplying the last equation by $q_{i}$, summing over all prices and using the fact that $\sum_{k=1}^{m} q_{k}=1$ yields

$$
\sum_{k=1}^{m} q_{k} p_{k}=\frac{t_{d}}{n^{2}}+\sum_{k=1}^{m} q_{k} r_{k}
$$

Inserting the last expression into $p_{i}$ gives

$$
p_{i}=\frac{1}{2}\left(r_{i}+\sum_{k=1}^{m} q_{k} r_{k}+\frac{2 t_{d}}{n^{2}}\right), \quad i \in\{1, \ldots m\} .
$$

Plugging $p_{i}$ into the expected profit (net of fixed costs and set-up costs) we get, after rearranging,

$$
\Pi^{i}\left(r_{i}, r_{-i}\right)=\frac{1}{4 t_{d} n^{3}}\left(2 t_{d}+n^{2}\left(\sum_{k=1}^{m} q_{k} r_{k}-r_{i}\right)\right)^{2}, \quad i \in\{1, \ldots, m\} .
$$

The next step is to determine the probabilities $q_{i}, i \in\{1, \ldots, m\}$. Inserting the last expression into 
(1) gives $^{52}$

$$
\begin{gathered}
q_{i}=\frac{1}{m}+\frac{1}{8 t_{u} t_{d} n^{3}} \times\left(2\left(2 t_{d}+n^{2}\left(\sum_{k=1}^{m} q_{k} r_{k}-r_{i}\right)\right)^{2}-\right. \\
\left.-\left(2 t_{d}+n^{2}\left(\sum_{k=1}^{m} q_{k} r_{k}-r_{((m+i-2) \bmod m)+1}\right)\right)^{2}-\left(2 t_{d}+n^{2}\left(\sum_{k=1}^{m} q_{k} r_{k}-r_{(i \bmod m)+1}\right)\right)^{2}\right), \quad i \in\{1, \ldots, m\} .
\end{gathered}
$$

Solving each of the $m$ equations for $q_{i}, i \in\{1, \ldots, m\}$ yields

$$
\begin{gathered}
q_{i}=\frac{1}{n\left(4 t_{u} t_{d}+r_{i} n\left(2 r_{i}-r_{(i \bmod m)+1}-r_{((i+m-2) \bmod m)+1}\right)\right)} \times \\
\times\left\{\frac{4 n t_{u} t_{d}}{m}-2 t_{d}\left(2 r_{i}-r_{(i \bmod m)+1}-r_{((i+m-2) \bmod m)+1}\right)+\frac{n^{2}}{2}[\right. \\
2 r_{i}-r_{(i \bmod m)+1}-r_{((i+m-2) \bmod m)+1}+2\left(q_{(i \bmod m)+1} r_{(i \bmod m)+1}^{2}+q_{((i+m-2) \bmod m)+1} r_{((i+m-2) \bmod m)+1}^{2}\right)- \\
-4 r_{i} \sum_{k=1, k \neq i}^{m} q_{k} r_{k}+2 r_{(i \bmod m)+1} r_{((i+m-2) \bmod m)+1}\left(q_{(i \bmod m)+1}+q_{((i+m-2) \bmod m)+1}\right)+ \\
\left.\left.+2\left(r_{(i \bmod m)+1}+r_{((i+m-2) \bmod m)+1}\right) \sum_{k=i, k \neq i}^{i+m-4} q_{(k+1 \bmod m)+1} r_{(k+1 \bmod m)+1}\right]\right\} .
\end{gathered}
$$

for $m \geq 3$ and

$$
q_{i}=\frac{2 n t_{u} t_{d}-4 t_{d}\left(r_{i}-r_{-i}\right)+n^{2}\left(r_{i}^{2} r_{-i}^{2}-2 q_{-i} r_{-i}\left(r_{i}-r_{-i}\right)\right)}{2 n\left(2 t_{u} t_{d}-n r_{i}\left(r_{i}-r_{-i}\right)\right)}
$$

for $m=2 .^{53}$

We are left with an inhomogeneous system of $m$ linear equations with $m$ unknowns. We may use the Gaussian algorithm to find $q_{i}, i \in\{1, \ldots, m\}$. Tedious but routine calculations yield the solution that can be written as

$$
\begin{gathered}
q_{i}\left(r_{i}, r_{-i}\right)=\frac{1}{m}+\frac{n^{2} m\left(2 r_{i}^{2}-r_{(i \bmod m)+1}^{2}-r_{((i+m-2) \bmod m)+1}^{2}\right)}{8 t_{u} t_{d}} \\
+\frac{n^{2} m\left(r_{i}\left(2 r_{i}-r_{(i \bmod m)+1}-r_{((i+m-2) \bmod m)+1}\right)\right)}{4 t_{u} t_{d}}-
\end{gathered}
$$

\footnotetext{
${ }^{52}$ Here and in the following, we make excessive use of the formulation $a \bmod b$. Because of the circular structure of the model, the left neighbor of firm 1 is firm $m$ and the right neighbor of firm $m$ is firm 1 . The operation $a$ mod $b$ allows us to write the formulas in the most general way. Recall that $a \bmod b$ is the remainder on division of $a$ by $b$. Since in our case $a<2 b$, we have that $a \bmod b$ is $a$, whenever $a<b$, and $a \bmod b$ is $a-b$, whenever $a \geq b$.

${ }^{53}$ The solution for $m=2$ cannot be incorporated in the general formula since, in contrast to $m \geq 3$, each firm has only one direct neighbor.
} 


$$
\begin{gathered}
-\frac{n^{2} m\left(2 r_{i}-r_{(i \bmod m)+1}-r_{((i+m-2) \bmod m)+1}\right)}{2 t_{u} t_{d} n^{2}\left(2 t_{u} t_{d}+n m \sum_{k=1}^{m} r_{k}\left(r_{k}-r_{(k \bmod m)+1}\right)\right)} \times \\
\times\left\{t_{u} t_{d}\left[2 t_{d}+\frac{n^{2}(m+1)}{m} r_{i}+\frac{n^{2}}{m} \sum_{k=1, k \neq i}^{m} r_{k}\right]+\right. \\
+\frac{n^{3} m}{8}\left[6 r_{i}^{3}+2 \sum_{k=1, k \neq i}^{m} r_{k}^{3}-5 r_{i}^{2}\left(r_{(i \bmod m)+1}+r_{((i+m-2) \bmod m)+1}\right)+\right. \\
+r_{i} \sum_{k=1, k \neq j}^{m} r_{k}^{2}(2+\min \{|k-i|,|m+i-k|\})-4 r_{i} \sum_{k=i}^{i+m-3} r_{(k \bmod m)+1} r_{(k+1 \bmod m)+1}- \\
\left.\left.-\sum_{k=i}^{i+m-3} r_{(k \bmod m)+1} r_{(k+1 \bmod m)+1}\left(r_{(k \bmod m)+1}+r_{(k+1 \bmod m)+1}\right)\right]\right\}
\end{gathered}
$$

for $m \geq 3$ and as

$$
q_{i}\left(r_{i}, r_{-i}\right)=\frac{t_{u} t_{d} n-4 t_{d}\left(r_{i}-r_{-i}\right)+n^{2}\left(r_{i}^{2}-r_{-i}^{2}\right)^{2}}{2\left(t_{u} t_{d}+n\left(r_{i}^{2}+r_{-i}^{2}-2 r_{i} r_{-i}\right)\right)}
$$

for $m=2$. Inserting these probabilities in (13) gives a downstream price of

$$
\begin{gathered}
p_{i}\left(r_{i}, r_{-i}\right)=\frac{1}{n^{2}\left(2 t_{u} t_{d}+n m \sum_{k=1}^{m} r_{k}\left(r_{k}-r_{(k \bmod m)+1}\right)\right)} \times \\
\times\left\{t_{u} t_{d}\left[2 t_{d}+\frac{n^{2}(m+1)}{m} r_{i}+\frac{n^{2}}{m} \sum_{k=1, k \neq i}^{m} r_{k}\right]+\right. \\
+\frac{n^{3} m}{8}\left[6 r_{i}^{3}+2 \sum_{k=1, k \neq i}^{m} r_{k}^{3}-5 r_{i}^{2}\left(r_{(i \bmod m)+1}+r_{((i+m-2) \bmod m)+1}\right)+\right. \\
+r_{i} \sum_{k=1, k \neq j}^{m} r_{k}^{2}(2+\min \{|k-i|,|m+i-k|\})-4 r_{i} \sum_{k=i}^{i+m-3} r_{(k \bmod m)+1} r_{(k+1 \bmod m)+1}- \\
\left.-\sum_{k=i}^{i+m-3} r_{(k \bmod m)+1} r_{(k+1 \bmod m)+1}\left(r_{(k \bmod m)+1}+r_{(k+1 \bmod m)+1)}\right]\right\}
\end{gathered}
$$

if $m \geq 3$, and

$$
p_{i}\left(r_{i}, r_{-i}\right)=\frac{4 t_{u} t_{d}^{2}+n^{2} t_{u} t_{d}\left(3 r_{i}+r_{-i}\right)+n^{3}\left(3 r_{i}^{3}+r_{-i}^{3}+r_{i} r_{-i}^{2}-5 r_{i}^{2} r_{2}\right)}{4 n^{2}\left(t_{u} t_{d}+n\left(r_{i}^{2}+r_{-i}^{2}-2 r_{i} r_{-i}\right)\right)}
$$

if $m=2$. 
Plugging the probabilities and prices back into the profit functions and solving for the quantity that a downstream firm buys from upstream firm $i$ yields

$$
\begin{gathered}
y_{i}\left(r_{i}, r_{-i}\right)=\frac{1}{n t_{d}\left(2 t_{u} t_{d}+n m \sum_{k=1}^{m} r_{k}\left(r_{k}-r_{(k \bmod m)+1}\right)\right)} \times \\
\left\{t_{u} t_{d}\left[2 t_{d}-\frac{n^{2}(m-1)}{m} r_{i}+\frac{n^{2}}{m} \sum_{k=1, k \neq i}^{m} r_{k}\right]+\right. \\
+\frac{n^{3} m}{8}\left[2 r_{i}^{3}+2 \sum_{k=1, k \neq i}^{m} r_{k}^{3}-6 r_{i}^{2}\left(r_{(i \bmod m)+1}+r_{((i+m-2) \bmod m)+1}\right)-\right. \\
-r_{i} \sum_{k=1, k \neq i}^{m} r_{k}^{2}(6-\min \{|k-i|,|m+i-k|\})+4 r_{i} \sum_{k=i}^{i+m-3} r_{(k \bmod m)+1} r_{(k+1 \bmod m)+1}- \\
\left.-\sum_{k=i}^{i+m-3} r_{(k \bmod m)+1} r_{(k+1 \bmod m)+1}\left(r_{(k \bmod m)+1}+r_{(k+1 \bmod m)+1)}\right]\right\},
\end{gathered}
$$

for $m \geq 3$ and

$$
y_{i}\left(r_{i}, r_{-i}\right)=\frac{4 t_{u} t_{d}^{2}-n^{2} t_{u} t_{d}\left(r_{i}-r_{-i}\right)-n^{3}\left(r_{i}^{3}-r_{-i}^{3}+3 r_{i} r_{-i}^{2}-3 r_{i}^{2} r_{-i}\right)}{4 n t_{d}\left(t_{u} t_{d}+n\left(r_{i}^{2}+r_{-i}^{2}-2 r_{i} r_{-i}\right)\right)}
$$

for $m=2$.

Having solved for the probabilities, the downstream prices and quantities, we proceed to the second stage, the upstream market.

As explained in Section 3, the profit function of an upstream firm can be written as

$$
\begin{gathered}
E\left[P_{i}\right]\left(r_{i}, r_{-i}\right)=r_{i} y_{i}\left(\left(\begin{array}{c}
n \\
1
\end{array}\right) q_{i}\left(1-q_{i}\right)^{n-1}+2\left(\begin{array}{c}
n \\
2
\end{array}\right) q_{i}^{2}\left(1-q_{i}\right)^{n-2}+\right. \\
\left.+\cdots+(n-1)\left(\begin{array}{c}
n \\
n-1
\end{array}\right) q_{i}^{n-1}\left(1-q_{i}\right)+n q_{i}^{n}\right)-F_{u},
\end{gathered}
$$

where, for notational simplicity, the arguments of $y_{i}$ and $q_{i}$ are suppressed. Rearranging terms gives

$$
\begin{gathered}
E\left[P_{i}\right]\left(r_{i}, r_{-i}\right)=r_{i} y_{i}\left(\sum_{j=1}^{n}\left(\begin{array}{c}
n \\
j
\end{array}\right) j q_{i}^{j}\left(1-q_{i}\right)^{n-j}\right)-F_{u}= \\
r_{i} y_{i}\left(r_{i}, r_{-i}\right) q_{i} n\left(\sum_{j=0}^{n-1}\left(\frac{(n-1) !}{j !(n-1-j) !}\right) q_{i}^{j}\left(1-q_{i}\right)^{n-1-j}\right)-F_{u} .
\end{gathered}
$$


We may use a modification of the Binomial Theorem ${ }^{54}$ to rewrite the profit function as

$$
E\left[P_{i}\right]\left(r_{i}, r_{-i}\right)=r_{i} y_{i} n q_{i}\left(q_{i}+\left(1-q_{i}\right)\right)^{n-1}=r_{i} y_{i} n q_{i}-F_{u} .
$$

We now can substitute (14) and (18) in case of $m \geq 3$ or (15) and (19) in case of $m=2$ in the last equation. Maximizing this profit function with respect to $r_{i}$ gives

$$
\frac{\partial E\left[P_{i}\right]\left(r_{i}, r_{i-1}, r_{i+1}\right)}{\partial r_{i}}=y_{i} q_{i}+r_{i}\left(q_{i} \frac{\partial y_{i}}{\partial r_{i}}+y_{i} \frac{\partial q_{i}}{\partial r_{i}}\right)=0, \quad i \in\{1, \ldots, m\} .
$$

Solving the system of equations $(20)$ for $r_{i}, i \in\{1, \ldots, m\}$, yields a symmetric solution that is given by

$$
r^{\star}=\frac{t_{u} t_{d} n}{\sum_{j=2}^{m} \frac{t_{u} n^{3}}{2 j(j-1)}+m^{2} t_{d}}=\frac{2 t_{u} t_{d} m n}{t_{u} n^{3}(m-1)+2 m^{3} t_{d}} .
$$

It is readily verified that the second order condition is satisfied at this solution. Inserting the equilibrium upstream prices into the formula for the downstream prices gives

$$
p^{\star}=\frac{t_{d}\left(m^{2} t_{d}+t_{u} n^{3}\left(1+\sum_{j=2}^{m} \frac{1}{2 j(j-1)}\right)\right)}{n^{2}\left(m^{2} t_{d}+t_{u} n^{3}\left(\sum_{j=2}^{m} \frac{1}{2 j(j-1)}\right)\right)}=\frac{t_{d}\left(2 m^{3} t_{d}+t_{u} n^{3}(3 m-1)\right)}{n^{2}\left(2 m^{3} t_{d}+t_{u} n^{3}(m-1)\right)} .
$$

Having solved for the equilibrium prices in both stages, we can proceed to the first stage and determine the equilibrium number of firms in both markets. This number is given by $n$ and $m$ that simultaneously solve the equations $E\left[\Pi_{j}\right]=0$ and $E\left[P_{i}\right]=0$. Inserting the equilibrium prices in the profit functions yields that $n^{\star}$ and $m^{\star}$ are implicitly defined by

$$
\frac{t_{d}}{\left(n^{\star}\right)^{3}}-\frac{t_{u}}{12\left(m^{\star}\right)^{2}}-F_{d}=0
$$

and

$$
\frac{2 t_{u} t_{d} n^{\star}}{t_{u}\left(n^{\star}\right)^{3}\left(m^{\star}-1\right)+2\left(m^{\star}\right)^{3} t_{d}}-F_{u}=0 .
$$

Given our assumptions on $F_{d}$ and $F_{u}$, an equilibrium exists in which at least two firms are active in both markets.

It remains to show uniqueness of the equilibrium. To this end, we first determine the iso-profitlines of a downstream and an upstream firm. For a downstream firm it is given by

$$
I_{D}:=\frac{\partial n}{\partial m}=\frac{t_{u}(n)^{4}}{18 t_{d}(m)^{3}}>0
$$

\footnotetext{
${ }^{54}$ Recall that the Binomial Theorem says that $\sum_{j=0}^{n}\left(\begin{array}{c}n \\ j\end{array}\right)(z)^{j}(y)^{n-j}=(y+z)^{n}$.
} 
and for an upstream firm it is given by

$$
I_{U}:=\frac{\partial m}{\partial n}=\frac{2\left((m)^{3} t_{d}-t_{u}(n)^{3}(m-1)\right)}{n\left(t_{u}(n)^{3}+6 t_{d}(m)^{2}\right)} .
$$

$I_{D}$ is increasing while $I_{U}$ is decreasing for $n>\sqrt[3]{\left(t_{d} m\right) /\left(t_{u}(m-1)\right)} m$ and increasing otherwise. Thus, a necessary condition for the two curves to cross more than once, and so for multiple equilibria to exist, is that the slope of $I_{U}$ in its increasing region is smaller than the slope of $I_{D}$. In an $m$ - $n$-plane the slope of $I_{U}$ is

$$
\frac{n\left(t_{u}(n)^{3}+6 t_{d}(m)^{2}\right)}{2\left((m)^{3} t_{d}-t_{u}(n)^{3}(m-1)\right)} .
$$

It is easy to see that the numerator of the last expression is bigger than the numerator of $I_{D}$ while the denominator is smaller than the denominator of $I_{D}$. It follows that the slope of $I_{U}$ is strictly steeper than the one of $I_{D}$ in the area when they are both increasing. As a consequence, the equilibrium is unique.

q.e.d.

\subsection{Appendix B}

\section{Proof of Proposition 2}

We start by looking at $F_{u}$. Differentiating (6) with respect to $F_{u}$ (taking into account that $n^{\star}$ and $m^{\star}$ vary with $F_{u}$ ) yields

$$
-3 \frac{t_{d}}{\left(n^{\star}\right)^{4}} \frac{d n^{\star}}{d F_{u}} d F_{u}+\frac{t_{u}}{6\left(m^{\star}\right)^{3}} \frac{d m^{\star}}{d F_{u}} d F_{u}=0 .
$$

Differentiating (7) with respect to $F_{u}$ gives

$$
\begin{gathered}
-2 \frac{t_{d} t_{u} n^{\star}\left(t_{u}\left(n^{\star}\right)^{3}+6\left(m^{\star}\right)^{2} t_{d}\right)}{\left(t_{u}\left(n^{\star}\right)^{3}(m-1)+2\left(m^{\star}\right)^{3} t_{d}\right)^{2}} \frac{d m^{\star}}{d F_{u}} d F_{u}-d F_{u}- \\
-\frac{4 t_{d} t_{u}\left(\left(t_{u}\left(n^{\star}\right)^{3}\left(m^{\star}-1\right)-\left(m^{\star}\right)^{3} t_{d}\right)^{2}\right)}{\left(t_{u}\left(n^{\star}\right)^{3}\left(m^{\star}-1\right)+2\left(m^{\star}\right)^{3} t_{d}\right)^{2}} \frac{d n^{\star}}{d F_{u}} d F_{u}=0 .
\end{gathered}
$$

Solving the last two equations for $\left(d m^{\star}\right) /\left(d F_{u}\right)$ and $\left(d n^{\star}\right) /\left(d F_{u}\right)$ gives

$$
\frac{d m^{\star}}{d F_{u}}=-\frac{9\left(m^{\star}\right)^{3}\left(t_{u}\left(n^{\star}\right)^{3}\left(m^{\star}-1\right)+2 t_{d}\left(m^{\star}\right)^{3}\right)^{2}}{2 t_{u} n^{\star}\left(8 t_{u} t_{d}\left(n^{\star}\right)^{3}\left(m^{\star}\right)^{3}+54 t_{d}^{2}\left(m^{\star}\right)^{5}+\left(n^{\star}\right)^{6}\left(m^{\star}-1\right) t_{u}^{2}\right)}<0
$$

and

$$
\frac{d n^{\star}}{d F_{u}}=-\frac{\left(n^{\star}\right)^{3}\left(t_{u}\left(n^{\star}\right)^{3}\left(m^{\star}-1\right)+2 t_{d}\left(m^{\star}\right)^{3}\right)^{2}}{4 t_{d}\left(8 t_{u} t_{d}\left(n^{\star}\right)^{3}\left(m^{\star}\right)^{3}+54 t_{d}^{2}\left(m^{\star}\right)^{5}+\left(n^{\star}\right)^{6}\left(m^{\star}-1\right) t_{u}^{2}\right)}<0,
$$


where the last inequality follows from the fact that $m^{\star} \geq 2$.

Proceeding in the same way as above concerning a change in $t_{u}$ gives

$$
\frac{d n^{\star}}{d t_{u}}=-\frac{\left(n^{\star}\right)^{4} m^{\star}\left(\left(n^{\star}\right)^{3} t_{u}+2\left(m^{\star}\right)^{2} t_{d}\right)}{4\left(8 t_{u} t_{d}\left(n^{\star}\right)^{3}\left(m^{\star}\right)^{3}+54 t_{d}^{2}\left(m^{\star}\right)^{5}+\left(n^{\star}\right)^{6}\left(m^{\star}-1\right) t_{u}^{2}\right)}<0
$$

and

$$
\frac{d m^{\star}}{d t_{u}}=\frac{m^{\star}\left(\left(n^{\star}\right)^{6} t_{u}^{2}\left(m^{\star}-1\right)+\left(m^{\star}\right)^{3} t_{d}\left(36\left(m^{\star}\right)^{2} t_{d}-t_{u}\left(n^{\star}\right)^{3}\right)\right)}{2 t_{u}\left(8 t_{u} t_{d}\left(n^{\star}\right)^{3}\left(m^{\star}\right)^{3}+54 t_{d}^{2}\left(m^{\star}\right)^{5}+\left(n^{\star}\right)^{6}\left(m^{\star}-1\right) t_{u}^{2}\right)}>0 .
$$

q.e.d.

\section{Proof of Proposition 3}

The proof proceeds along similar lines as the proof of Proposition 2. Differentiating (6) and (7) with respect to $F_{d}$ and solving the resulting equations for $d n^{\star} / d F_{d}$ and $d m^{\star} / d F_{d}$ gives

$$
\frac{d n^{\star}}{d F_{d}}=-\frac{3\left(n^{\star}\right)^{4}\left(m^{\star}\right)^{3}\left(t_{u}\left(n^{\star}\right)^{3}+6\left(m^{\star}\right)^{2} t_{d}\right)}{\left(8 t_{u} t_{d}\left(n^{\star}\right)^{3}\left(m^{\star}\right)^{3}+54 t_{d}^{2}\left(m^{\star}\right)^{5}+\left(n^{\star}\right)^{6}\left(m^{\star}-1\right) t_{u}^{2}\right)}<0
$$

and

$$
\frac{d m^{\star}}{d F_{d}}=\frac{6\left(m^{\star}\right)^{3}\left(n^{\star}\right)^{3}\left(t_{u}\left(n^{\star}\right)^{3}\left(m^{\star}-1\right)-\left(m^{\star}\right)^{3} t_{d}\right)}{8 t_{u} t_{d}\left(n^{\star}\right)^{3}\left(m^{\star}\right)^{3}+54 t_{d}^{2}\left(m^{\star}\right)^{5}+\left(n^{\star}\right)^{6}\left(m^{\star}-1\right) t_{u}^{2}} .
$$

It is obvious that $\left(d m^{\star}\right) /\left(d F_{d}\right) \geq 0$ if $n^{\star} \geq \sqrt[3]{\left(m^{\star} t_{d}\right) /\left(\left(m^{\star}-1\right) t_{u}\right)} m^{\star}$ and $\left(d m^{\star}\right) /\left(d F_{d}\right)<0$ if $n^{\star}<$ $\sqrt[3]{\left(m^{\star} t_{d}\right) /\left(\left(m^{\star}-1\right) t_{u}\right)} m^{\star}$. Since $\left(d n^{\star}\right) /\left(d F_{d}\right)<0$, there exists an $F_{d}$ denoted by $\bar{F}_{d}$ such that $m^{\star}$ is increasing (decreasing) in $F_{d}$ as long as $F_{d}<(>) \bar{F}_{d}$.

Now we turn to $t_{d}$. Differentiating (6) and (7) with respect to $t_{d}$ and solving the resulting two equations for $\left(d n^{\star}\right) /\left(d t_{d}\right)$ and $\left(d m^{\star}\right) /\left(d t_{d}\right)$ gives

$$
\frac{d n^{\star}}{d t_{d}}=\frac{n^{\star}\left(\left(n^{\star}\right)^{6} t_{u}^{2}\left(m^{\star}-1\right)+6\left(m^{\star}\right)^{3} t_{d}\left(6\left(m^{\star}\right)^{2} t_{d}+\left(n^{\star}\right)^{3} t_{u}\right)\right)}{2 t_{d}\left(8 t_{u} t_{d}\left(n^{\star}\right)^{3}\left(m^{\star}\right)^{3}+54 t_{d}^{2}\left(m^{\star}\right)^{5}+\left(n^{\star}\right)^{6}\left(m^{\star}-1\right) t_{u}^{2}\right)}>0
$$

and

$$
\frac{d m^{\star}}{d t_{d}}=\frac{3\left(m^{\star}\right)^{3}\left(2 t_{d}\left(m^{\star}\right)^{3}+t_{u}\left(n^{\star}\right)^{3}\left(m^{\star}-1\right)\right)}{8 t_{u} t_{d}\left(n^{\star}\right)^{3}\left(m^{\star}\right)^{3}+54 t_{d}^{2}\left(m^{\star}\right)^{5}+\left(n^{\star}\right)^{6}\left(m^{\star}-1\right) t_{u}^{2}}>0 .
$$

q.e.d. 


\section{Proof of Proposition 4}

We first consider a change in $t_{d}$. Differentiating the welfare function (10) with respect to $t_{d}$ and using $d n^{\star} / d t d$ and $d m^{\star} / d t d$ from Proposition 3 yields

$$
\frac{d W F}{d t d}=-\frac{t_{d}\left(m^{\star}\right)^{3}\left(117 t_{d}\left(m^{\star}\right)^{2}+49 t_{u}\left(n^{\star}\right)^{3}\right)}{6\left(n^{\star}\right)^{2}\left(8 t_{u} t_{d}\left(n^{\star}\right)^{3}\left(m^{\star}\right)^{3}+54 t_{d}^{2}\left(m^{\star}\right)^{5}+\left(n^{\star}\right)^{6}\left(m^{\star}-1\right) t_{u}^{2}\right)} .
$$

When ignoring the upstream market, i.e. ignoring the effect that $m^{\star}$ changes in $t_{d}$, we get from 6 that

$$
\left.\frac{d n^{\star}}{d t d}\right|_{\frac{d m^{\star}}{d t d}=0}=\frac{n^{\star}}{3 t_{d}}
$$

and thus

$$
\left.\frac{d W F}{d t d}\right|_{\frac{d m^{\star}}{d t d}=0}=-\frac{t_{u}\left(n^{\star}\right)^{3}\left(37 m^{\star}-13\right)+26 t_{d}\left(m^{\star}\right)^{3}}{36\left(n^{\star}\right)^{2}\left(t_{u}\left(n^{\star}\right)^{3}\left(m^{\star}-1\right)+2 t_{d}\left(m^{\star}\right)^{3}\right)} .
$$

Subtracting (22) from (21) gives

$$
\frac{t_{u} n^{\star}\left(4 t_{d} t_{u}\left(n^{\star}\right)^{3}\left(m^{\star}\right)^{3}\left(7 m^{\star}+41\right)+916 t_{d}^{2}\left(m^{\star}\right)^{6}+t_{u}^{2}\left(n^{\star}\right)^{6}\left(37\left(m^{\star}\right)^{2}-50 m^{\star}+13\right)\right)}{36\left(8 t_{u} t_{d}\left(n^{\star}\right)^{3}\left(m^{\star}\right)^{3}+54 t_{d}^{2}\left(m^{\star}\right)^{5}+\left(n^{\star}\right)^{6}\left(m^{\star}-1\right) t_{u}^{2}\right)\left(t_{u}\left(n^{\star}\right)^{3}\left(m^{\star}-1\right)+2 t_{d}\left(m^{\star}\right)^{3}\right)}>0 .
$$

Since both (21) and (22) are negative, it follows that the absolute value of $\left.(d W F / d t d)\right|_{d m^{\star} / d t d=0}$ is higher than the absolute value of $(d W F / d t d)$. Hence, the welfare effect of changing $t_{d}$ is overestimated when ignoring the upstream market.

Proceeding in the same way for a change in $F_{d}$ yields

$$
\begin{gathered}
\left.\left(\frac{d W F}{d F_{d}}-\frac{d W F}{d F_{d}}\right)\right|_{\frac{d m^{\star}}{d t d}=0}=t_{u}\left(n^{\star}\right)^{4}\left(t_{u}\left(n^{\star}\right)^{3}\left(m^{\star}-1\right)-t_{d}\left(m^{\star}\right)^{3}\right) \times \\
\frac{\left(4 t_{d} t_{u}\left(n^{\star}\right)^{3}\left(m^{\star}\right)^{3}\left(7 m^{\star}+41\right)+916 t_{d}^{2}\left(m^{\star}\right)^{6}+t_{u}^{2}\left(n^{\star}\right)^{6}\left(37\left(m^{\star}\right)^{2}-50 m^{\star}+13\right)\right)}{18\left(8 t_{u} t_{d}\left(n^{\star}\right)^{3}\left(m^{\star}\right)^{3}+54 t_{d}^{2}\left(m^{\star}\right)^{5}+\left(n^{\star}\right)^{6}\left(m^{\star}-1\right) t_{u}^{2}\right)\left(t_{u}\left(n^{\star}\right)^{3}\left(m^{\star}-1\right)+2 t_{d}\left(m^{\star}\right)^{3}\right)} .
\end{gathered}
$$

It follows that the right hand side of $(24)$ is positive if $n<\sqrt[3]{\left(t_{d} m^{\star}\right) /\left(t_{u}\left(m^{\star}-1\right)\right)} m^{\star}$. Since both $\left(d W F / d F_{d}\right)$ and $\left.\left(d W F / d F_{d}\right)\right|_{d m^{\star} / d t d=0}$ are negative, it follows that the first one is of larger magnitude than the latter if and only if $n<\sqrt[3]{\left(t_{d} m^{\star}\right) /\left(t_{u}\left(m^{\star}-1\right)\right)} m^{\star}$. Since $n^{\star}$ is a decreasing function of $F_{d}$, there exists an $\bar{F}_{d}$ such that the magnitude of $\left(d W F / d F_{d}\right)$ is larger than $\left.\left(d W F / d F_{d}\right)\right|_{d m^{\star} / d t d=0}$, if and only if $F_{d}>\bar{F}_{d}$ and vice versa.

q.e.d. 


\section{Proof of Corollary 1}

The magnitude of the overestimation is given by (23). Differentiating (23) with respect to $t_{u}$ yields

$$
\frac{t_{d} n^{\star}\left(m^{\star}\right)^{3} \xi}{6\left(8 t_{u} t_{d}\left(n^{\star}\right)^{3}\left(m^{\star}\right)^{3}+54 t_{d}^{2}\left(m^{\star}\right)^{5}+\left(n^{\star}\right)^{6}\left(m^{\star}-1\right) t_{u}^{2}\right)^{2}\left(t_{u}\left(n^{\star}\right)^{3}\left(m^{\star}-1\right)+2 t_{d}\left(m^{\star}\right)^{3}\right)^{2}}>0,
$$

where

$$
\begin{aligned}
& \xi=\left(16488 t_{d}^{4}\left(m^{\star}\right)^{11}+t_{d}^{3} t_{u}\left(n^{\star}\right)^{3}\left(m^{\star}\right)^{8}\left(1008\left(m^{\star}\right)+5904\right)+t_{d}^{2} t_{u}^{2}\left(n^{\star}\right)^{6}\left(m^{\star}\right)^{5}\left(798\left(m^{\star}\right)^{2}+488 m^{\star}-774\right)+\right. \\
& \left.+t_{d} t_{u}^{2}\left(n^{\star}\right)^{9}\left(m^{\star}\right)^{2}\left(558\left(m^{\star}\right)^{3}-1222\left(m^{\star}\right)^{2}+898 m^{\star}-234\right)+t_{u}^{4}\left(n^{\star}\right)^{12}\left(57\left(m^{\star}\right)^{3}-163\left(m^{\star}\right)^{2}+155 m^{\star}-49\right)\right)>0 .
\end{aligned}
$$

The inequality follows from $m^{\star} \geq 2$.

Differentiating (23) with respect to $m^{\star}$ yields

$$
-\frac{t u n^{\star}\left(m^{\star}\right)^{3} \xi}{6\left(8 t_{u} t_{d}\left(n^{\star}\right)^{3}\left(m^{\star}\right)^{3}+54 t_{d}^{2}\left(m^{\star}\right)^{5}+\left(n^{\star}\right)^{6}\left(m^{\star}-1\right) t_{u}^{2}\right)^{2}\left(t_{u}\left(n^{\star}\right)^{3}\left(m^{\star}-1\right)+2 t_{d}\left(m^{\star}\right)^{3}\right)^{2}}<0 .
$$

Finally, differentiating (23) with respect to $t_{d}$ yields

$$
-\frac{t u n^{\star} \psi}{6\left(8 t_{u} t_{d}\left(n^{\star}\right)^{3}\left(m^{\star}\right)^{3}+54 t_{d}^{2}\left(m^{\star}\right)^{5}+\left(n^{\star}\right)^{6}\left(m^{\star}-1\right) t_{u}^{2}\right)^{2}\left(t_{u}\left(n^{\star}\right)^{3}\left(m^{\star}-1\right)+2 t_{d}\left(m^{\star}\right)^{3}\right)^{2}}<0,
$$

with

$$
\begin{gathered}
\psi=32976 t_{d}^{5}\left(m^{\star}\right)^{13}+t_{d}^{4} t_{u}\left(n^{\star}\right)^{3}\left(m^{\star}\right)^{10}\left(2016\left(m^{\star}+23004\right)\right)+t_{d}^{3} t_{u}^{2}\left(n^{\star}\right)^{6}\left(m^{\star}\right)^{7}\left(3768\left(m^{\star}\right)^{2}+1596 m^{\star}-1080\right) \\
+t_{d}^{2} t_{u}^{3}\left(n^{\star}\right)^{9}\left(m^{\star}\right)^{4}\left(1116\left(m^{\star}\right)^{3}-2069\left(m^{\star}\right)^{2}+11794 m^{\star}-585\right)+ \\
t_{d} t_{u}^{4}\left(n^{\star}\right)^{12}\left(m^{\star}\right)^{2}\left(114\left(m^{\star}\right)^{3}-311\left(m^{\star}\right)^{2}+344 m^{\star}-147\right)+4 t_{u}^{5}\left(n^{\star}\right)^{15}\left(\left(m^{\star}\right)^{2}-2 m^{\star}+1\right)>0 .
\end{gathered}
$$

q.e.d.

\section{Proof of Proposition 5}

We are interested in the difference

$$
\left|\frac{d W F}{d F_{d}}\right|-\left|\frac{d W F}{d F_{u}}\right|
$$

With a change in $F_{i}, i \in\{u, d\}$ the equilibrium number of firms changes and so

$$
\left|\frac{d W F}{d F_{i}}\right|=\left|\frac{\partial W F}{\partial m^{\star}} \frac{\partial m^{\star}}{\partial F_{i}}\right|+\left|\frac{\partial W F}{\partial n^{\star}} \frac{\partial n^{\star}}{\partial F_{i}}\right|
$$


Substituting $\left(\partial m^{\star}\right) /\left(\partial F_{i}\right)$ and $\left(\partial n^{\star}\right) /\left(\partial F_{i}\right)$ from the proof of Proposition 2 in the last equation and simplifying yields

$$
\begin{gathered}
\left|\frac{d W F}{d F_{d}}\right|= \\
\frac{t d n^{\star}\left(m^{\star}\right)^{3}\left(37 t u^{2} n^{6} m^{\star}-37 t u^{2}\left(n^{\star}\right)^{6}+80\left(m^{\star}\right)^{3} t d t u\left(n^{\star}\right)^{3}\right)}{2\left(2\left(m^{\star}\right)^{3} t d+t u\left(n^{\star}\right)^{3} m^{\star}-\left(n^{\star}\right)^{3} t u\right)\left(8\left(m^{\star}\right)^{3} t d t u\left(n^{\star}\right)^{3}+54\left(m^{\star}\right)^{5} t d^{2}+t u^{2}\left(n^{\star}\right)^{6} m^{\star}-t u^{2}\left(n^{\star}\right)^{6}\right)} \\
+\frac{t d n^{\star}\left(m^{\star}\right)^{3}\left(-78\left(n^{\star}\right)^{3} t d t u\left(m^{\star}\right)^{2}+156\left(m^{\star}\right)^{5} t d^{2}\right)}{2\left(2\left(m^{\star}\right)^{3} t d+t u\left(n^{\star}\right)^{3} m^{\star}-\left(n^{\star}\right)^{3} t u\right)\left(8\left(m^{\star}\right)^{3} t d t u\left(n^{\star}\right)^{3}+54\left(m^{\star}\right)^{5} t d^{2}+t u^{2}\left(n^{\star}\right)^{6} m^{\star}-t u^{2}\left(n^{\star}\right)^{6}\right)}
\end{gathered}
$$

and

$$
\begin{aligned}
\left|\frac{d W F}{d F_{u}}\right| & \left.=\frac{28\left(m^{\star}\right)^{4} t d t u\left(n^{\star}\right)^{3}+37 t u^{2}\left(n^{\star}\right)^{6}\left(m^{\star}\right)^{2}-50 t u^{2}\left(n^{\star}\right)^{6} m^{\star}}{24\left(8\left(m^{\star}\right)^{3} t d t u\left(n^{\star}\right)^{3}+54\left(m^{\star}\right)^{5} t d^{2}+t u^{2}\left(n^{\star}\right)^{6} m^{\star}-t u^{2}\left(n^{\star}\right)^{6}\right.}\right)+ \\
+ & \left.\frac{164\left(m^{\star}\right)^{3} t d t u\left(n^{\star}\right)^{3}+13 t u^{2}\left(n^{\star}\right)^{6}+916\left(m^{\star}\right)^{6} t d^{2}}{24\left(8\left(m^{\star}\right)^{3} t d t u\left(n^{\star}\right)^{3}+54\left(m^{\star}\right)^{5} t d^{2}+t u^{2}\left(n^{\star}\right)^{6} m^{\star}-t u^{2}\left(n^{\star}\right)^{6}\right.}\right) .
\end{aligned}
$$

Inserting $t_{d}=t_{u}$ and $n^{\star}=m^{\star}$ in the last equations and determining the difference gives

$$
\left|\frac{d W F}{d F_{d}}\right|-\left|\frac{d W F}{d F_{u}}\right|=429\left(m^{\star}\right)^{2}-37\left(m^{\star}\right)^{3}-157-555 m^{\star} .
$$

It remains to show that there is a unique solution with $m^{\star} \geq 2$ to the equation

$$
-37\left(m^{\star}\right)^{3}+429\left(m^{\star}\right)^{2}-157-555 m^{\star}=0,
$$

and that the left hand side of $(25)$ is bigger than zero for all $m<\tilde{m}$. The left hand side of $(25)$ is a cubic equation in $m^{\star}$ with a negative leading term. Thus, it is negative as $m^{\star}$ grows large. On the other hand, it is positive at $m^{\star}=2$ while it is negative again at $m^{\star}$ close to zero. This shows that there is indeed a unique $m^{\star}>2$, denoted by $\tilde{m}$, such that (25) is fulfilled, and that for all $m^{\star}$ with $2 \leq m^{\star}<\tilde{m}$ the left hand side of $(25)$ is positive.

q.e.d.

\section{Proof of Proposition 6}

The proof proceeds along similar lines as the proof of Proposition 5. Here we are interested in the difference

$$
\left|\frac{d W F}{d t_{d}}\right|-\left|\frac{d W F}{d t_{u}}\right|
$$


where

$$
\left|\frac{d W F}{d t_{i}}\right|=\left|\frac{\partial W F}{\partial t_{i}}\right|+\left|\frac{\partial W F}{\partial m^{\star}} \frac{\partial m^{\star}}{\partial t_{i}}\right|+\left|\frac{\partial W F}{\partial n^{\star}} \frac{\partial n^{\star}}{\partial t_{i}}\right| .
$$

Substituting $\left(\partial m^{\star}\right) /\left(\partial t_{i}\right)$ and $\left(\partial n^{\star}\right) /\left(\partial t_{i}\right)$ from the proof of Proposition 3 in the last equation, setting $t_{d}$ equal to $t_{u}$ and $n^{\star}$ equal to $m^{\star}$, and simplifying yields

$$
\left|\frac{d W F}{d t_{d}}\right|-\left|\frac{d W F}{d t_{u}}\right|=-37\left(m^{\star}\right)^{3}+205\left(m^{\star}\right)^{2}-226 m^{\star}+468 .
$$

By the same way as in the proof of Proposition 7 one can show that there exists a unique $m^{\prime}>2$ such that $\left|d W F / d t_{d}\right|-\left|d W F / d t_{u}\right|>0$ if and only if $m<m^{\prime}$.

q.e.d.

\subsection{Appendix $\mathrm{C}$}

\section{Proof of Proposition 8}

We start with proving $m^{\star}<m_{t p}^{\star}$. The proof proceeds by way of contradiction.

First look at the equilibrium under linear prices. Solving the zero profit condition on the downstream market for $n^{\star}$ yields

$$
n^{\star}=\sqrt[3]{\frac{12 t_{d}\left(m^{\star}\right)^{2}}{t_{u}+12 F_{d}\left(m^{\star}\right)^{2}}} .
$$

Inserting this into the zero profit condition on the upstream market gives

$$
\frac{t_{u} \sqrt[3]{12 t_{d}\left(m^{\star}\right)^{2}\left(t_{u}+12 F_{d}\left(m^{\star}\right)^{2}\right)^{2}}}{\left(m^{\star}\right)^{2}\left(t_{u}\left(7 m^{\star}-6\right)+12 F_{d}\left(m^{\star}\right)^{3}\right)}=F_{u} .
$$

Proceeding in the same way for the case of non linear prices yields

$$
\frac{t_{u} \sqrt[3]{12 t_{d}\left(m_{t p}^{\star}\right)^{2}}}{\left(m_{t p}^{\star}\right)^{3} \sqrt[3]{13 t_{u}+12 F_{d}\left(m_{t p}^{\star}\right)^{2}}}=F_{u} .
$$

Now suppose that $m_{t p}^{\star}=m^{\star}=m$. In this case the left hand sides of the last two equations must be the same since otherwise the profit in the upstream market in the two regimes would be different. Subtracting the left hand side of (27) from the left hand side of (26) and simplifying gives

$$
\begin{gathered}
\left(t_{u}+12 F_{d} m^{2}\right)^{2}\left(13 t_{u}+12 F_{d} m^{2}\right)^{3} m^{3}-\left(7 t_{u} m-6 t_{u}+12 F_{d} m^{3}\right)^{3}\left(13 t_{u}+12 F_{d} m^{2}\right)^{2}= \\
=-6 t_{u}\left(13 t_{u}+12 F_{d} m^{2}\right)^{2}\left[t_{u}^{2}\left(55 m^{3}-36+126 m-147 m^{2}\right)+\right. \\
\left.+t_{u} m^{3} F_{d}\left(240 m^{2}+216-504 m\right)+F_{d}^{2} m^{6}(144 m-288)\right]<0
\end{gathered}
$$


where the last inequality follows from the fact that $m \geq 2$. Thus, if the number of upstream firms would be the same under the two regimes, the profit under two-part tariffs would be higher. Since upstream profit is decreasing in $m$, it follows that $m^{\star}<m_{t p}^{\star}$.

We now show that $n^{\star}>n_{t p}^{\star}$. Suppose to the contrary that $n^{\star} \leq n_{t p}^{\star}$. If this were the case, the downstream profit (net of set-up costs) under two-part tariffs must be higher than the one under linear pricing, i.e.

$$
\frac{t_{d}}{\left(n_{t p}^{\star}\right)^{3}}-\frac{13 t_{u}}{12\left(m_{t p}^{\star}\right)^{2}} \geq \frac{t_{d}}{\left(n^{\star}\right)^{3}}-\frac{t_{u}}{12\left(m^{\star}\right)^{2}} .
$$

It is obvious that this can only be the case if $m_{t p}^{\star} \geq \sqrt{13} m^{\star}$. Now let us check if this can be possible. Inserting $m_{t p}^{\star}=\sqrt{13} m^{\star}$ into $(27)$ gives

$$
\frac{13^{(5 / 6)} t_{u} \sqrt[3]{2028 t_{d}\left(m^{\star}\right)^{2}}}{2197\left(m^{\star}\right)^{3} \sqrt[3]{\left(t_{u}+12 F_{d}\left(m^{\star}\right)^{2}\right)^{2}}}=F_{u} .
$$

Subtracting the left hand side of the last equation from the left hand side of (26), namely the upstream profit (net of set-up costs) under linear pricing, and simplifying the resulting expression reveals that the sign of this difference is given by the sign of

$$
t_{u}\left(2197 m^{\star}-13^{(5 / 6)} \cdot 169^{(1 / 3)}\left(7 m^{\star}-6\right)\right)+F_{d}\left(m^{\star}\right)^{3}\left(26364-12 \cdot 13^{(5 / 6)} \cdot 169^{(1 / 3)}\right) .
$$

Since $m^{\star} \geq 2$, this expression is positive. But the consequence would be that $m^{\star}>m_{t p}^{\star}$, contradicting the fact that $m^{\star}<m_{t p}^{\star}$. It follows that $m_{t p}^{\star}<\sqrt{13} m^{\star}$ and so $n^{\star}>n_{t p}^{\star}$.

q.e.d.

\section{Proof of Proposition 9}

We know that the equilibrium number of downstream and upstream firms under under two-part tariffs are implicitly defined by

$$
\frac{t_{d}}{\left(n_{t p}^{\star}\right)^{3}}-\frac{13 t_{u}}{12\left(m_{t p}^{\star}\right)^{2}}=F_{d}
$$

and

$$
\frac{t_{u} n_{t p}^{\star}}{\left(m_{t p}^{\star}\right)^{3}}=F_{u} .
$$

Solving (28) for $m_{t p}^{\star}$ and inserting in (29) yields that $n_{t p}^{\star}$ is implicitly given by

$$
\frac{24 \sqrt{39}\left(t_{d}-F_{d}\left(n_{t p t}^{\star}\right)^{3}\right)^{(3 / 2)}}{169 \sqrt{t_{u}}\left(n_{t p t}^{\star}\right)^{(7 / 2)}}=F_{u} .
$$


Proceeding in the same way for the linear pricing regime, namely solving (6) for $m^{\star}$ and inserting in (7) yields that $n^{\star}$ is implicitly defined by

$$
\frac{72 t_{u} t_{d}\left(t_{d}-F_{d}\left(n^{\star}\right)^{3}\right)^{(3 / 2)}}{\left(n^{\star}\right)^{2}\left(6 t_{u} n^{\star} \sqrt{3 t_{u} n^{\star}}\left(t_{d}-F_{d}\left(n^{\star}\right)^{3}\right)-36 t_{u}\left(t_{d}-F_{d}\left(n^{\star}\right)^{3}\right)^{(3 / 2)}+t_{d} \sqrt{3}\left(t_{u} n^{\star}\right)^{(3 / 2)}\right)}=F_{u} .
$$

Now welfare under linear prices is larger than under two-part tariffs if and only if

$$
W F_{l p}=a-\frac{t_{d}\left(26\left(m^{\star}\right)^{3} t_{d}+t_{u}\left(n^{\star}\right)^{3}\left(37 m^{\star}-13\right)\right)}{12\left(n^{\star}\right)^{2}\left(2\left(m^{\star}\right)^{3} t_{d}+t_{u}\left(n^{\star}\right)^{3}\left(m^{\star}-1\right)\right)} \geq a-\frac{13 t_{d}}{12\left(n_{t p}^{\star}\right)^{2}}=W F_{t p} .
$$

Solving (6) for $m^{\star}$, plugging the result into (32) and solving for $n_{t p}^{\star}$ yields

$$
n^{\star}\left(\frac{\sqrt{13}\left(\sqrt{3} t_{d}\left(t_{u} n^{\star}\right)^{(3 / 2)}+6 t_{u}\left(t_{d}-F_{d}\left(n^{\star}\right)^{3}\right)\left(n^{\star} \sqrt{3 t_{u} n^{\star}}-6 \sqrt{t_{d}-F_{d}\left(n^{\star}\right)^{3}}\right)\right)}{\sqrt{3} t_{d}\left(t_{u} n^{\star}\right)^{(3 / 2)}+6 t_{u}\left(t_{d}-F_{d}\left(n^{\star}\right)^{3}\right)\left(37 n^{\star} \sqrt{3 t_{u} n^{\star}}-78 \sqrt{t_{d}-F_{d}\left(n^{\star}\right)^{3}}\right)}\right)^{(1 / 2)} \geq n_{t p}^{\star},
$$

which is $(12)$.

We can now easily show by means of an example that welfare under linear prices can either be higher or lower than under two-part tariffs. Suppose that $t_{d}=1, t_{u}=5, F_{d}=0.001$ and $F_{u}=0.01$. In this case from $(31)$ we get $n^{\star}=4.971$ and from (30) we get $n_{t p}^{\star}=2.8339$. Determining the right hand side of (12) yields $3.002>2.8339$ and so welfare under two-part pricing is lower than under linear tariffs. On the other hand, if $t_{d}=1, t_{u}=1, F_{d}=0.001$ and $F_{u}=0.0005$, we get $n^{\star}=9.470$ and $n_{t p}^{\star}=7.048$, while the value of the right hand side of $(12)$ is $6.877<7.048$. Thus, welfare under two-part tariffs is higher than under linear pricing.

q.e.d. 


\section{References}

P. Aghion and M. Schankerman (2004): "On the Welfare Effects and Political Economy of CompetitionEnhancing Policies," Economic Journal , 114, 800-834.

O. Blanchard and F. Giavazzi (2003): "Macroeconomic Effects of Regulation and Deregulation in Goods and Labor Markets "Quarterly Journal of Economics , 103, 879-907.

Y. Chen (2001): "On Vertical Mergers and their Competitive Effects," RAND Journal of Economics, $32,667-685$.

P.W. Dobson and M. Waterson (2007): "The Competition Effects of Industry-Wide Vertical Price Fixing in Bilateral Oligopoly,"Working Paper, University of Warwick.

M.J. Doane and D.F. Spulber (1994): "Open Access and the Evolution of the U.S. Spot Market for Natural Gas," Journal of Law and Economics, 37, 477-517.

Energy Information Administration (2006): "Additions to Capacity on the Natural Gas Pipeline Network: 2005," available at: http://www.eia.doe.gov/pub/oil_gas/natural_gas/feature_articles/2006/ ngpipeline/ngpipeline.pdf

P. Eső, V. Nocke and L. White (2006): "Competition for Scarce Resources,", Working Paper, Northwestern University.

J.J. Gabszewicz, and J.-F. Thisse (1986): "Spatial Competition and the Location of Firms," in: Location Theory, Fundamentals in Pure and Applied Economics, ed.: J. Lesourne and H. Sonnenschein, Harwood Academic Publishers, London, 1-71.

G. Gaudet and N. van Long (1996): "Vertical Integration, Foreclosure, and Profit in the Presence of Double Marginalization," Journal of Economics and Management Strategy, 5 , 409-432.

A. Ghosh and H. Morita (2007): "Free Entry and Social Efficiency under Vertical Oligopoly," RAND Journal of Economics, forthcoming.

D. Gordon and P. Kshemendranath (1999): "Setting up of Ready-Mixed Concrete Industry in India: The Challenge and Opportunities," in: Utilizing Ready-Mixed Concrete and Mortar, ed.: R.K. Dhir and M.C. Limbachiya, Thomas Telford, London, 211-220.

M.K. Greenhut and H. Ohta (1979): "Vertical Integration in Successive Oligopolies," American 
Economic Review, 69, 137-141.

O. Hart and J. Tirole (1990): "Vertical Integration and Market Foreclosure," Brookings Papers on Economic Activity: Microeconomics, 205-276.

K. Hendricks and R.P. McAfee (2007): "A Theory of Bilateral Oligopoly,", Working Paper, California Institute of Technology.

N.G. Mankiw and M.D. Whinston (1986): "Free Entry and Social Efficiency," RAND Journal of Economics, 17, 48-58.

R.P McAfee and P.J. Reny (2007): "The Role of Excess Capacity in Determining Market Power in Natural Gas Transportation Markets," Journal of Regulatory Economics, 32, 209-223.

R.P. McAfee and M. Schwartz (1994): "Opportunism in Multilateral Vertical Contracting: NonDiscrimination, Exclusivity and Uniformity," American Economic Review, 84, 210-230.

G. Nicoletti and S. Scarpetta (2003): "Regulation, Productivity and Growth: OECD Evidence," Economic Policy, 36, 9-72.

OECD (2000): "Promoting Competition in the Natural Gas Industry,"Unclassified Paper.

J.A. Ordover and J.C. Panzar (1982): "On the Nonlinear Pricing of Inputs," International Economic Review, 23, 659-675.

J.A. Ordover, G Saloner, and S.C. Salop (1990): "Equilibrium Vertical Foreclosure," American Economic Review, 80, 127-142.

M. Raith (2003): “Competition, Risk, and Managerial Incentives," American Economic Review, 93, $1425-1436$.

P. Rey and J. Tirole (2007): "A Primer on Foreclosure,"in: Handbook of Industrial Organization, Vol. 3, eds.: M. Armstrong and R.H. Porter, Elsevier B.V., North Holland, Amsterdam, 2145-2220.

P. Rey and T. Vergé (2004): "Resale Price Maintenance and Horizontal Cartel,"Working Paper, University of Toulouse.

M.A. Salinger (1988): "Vertical Merger and Market Foreclosure," Quarterly Journal of Economics, $103,345-356$. 
S.C. Salop (1979): "Monopolistic Competition with Outside Goods," Bell Journal of Economics, 10, 141-156.

C. Syverson (2004): "Market Structure and Productivity: A Concrete Example," Journal of Political Economy, 112, 1181-1222.

S.B. Villas-Boas (2007): "Vertical Relationships between Manufacturers and Retailers: Inference with Limited Data," Review of Economic Studies, 74, 625-652.

L. White (2007): "Foreclosure with Incomplete Information," Journal of Economics and Management Strategy, 16, 507-535. 